\title{
El Pacífico suramericano y su integración con China y Asia
}

\author{
The South American Pacific and its integration \\ with China and Asia
}

\section{Países do Pacífico e integração sul-americana com a China e Ásia.}

Jaime Torres González *

DOI: https://doi.org/10.19053/01203053.v37.n65.2018.5886

Fecha de recepción: 24 de febrero de 2017

Fecha de aprobación: 25 de agosto de 2017

* Ph.D. en Ciencias Políticas de la Universidad Libre de Berlín. Profesor titular del programa de Comercio Internacional de la Universidad de Bogotá Jorge Tadeo Lozano. Bogotá, Colombia Correo electrónico jaime. torresg@utadeo.edu.co. (iD) orcid.org/0000-0002-0340-8613 


\section{Resumen}

El presente trabajo confronta las políticas industriales seguidas por las naciones suramericanas con las de los países del Sureste del Asia y plantea que la influencia del Consenso de Washington en las primeras permitió desvertebrar su desarrollo industrial, mientras que el tipo de desarrollo económico en Asia ha sido más exitoso, enmarcado en las últimas décadas en lo que se conoce como Consenso de Beijing. Para ello se hace un estudio comparativo de la evolución de diferentes indicadores económicos y sociales de las naciones suramericanas, así como de Malasia, Tailandia y Vietnam, utilizando datos de comercio de las Naciones Unidas-Comtrade e indicadores del World Development Report 2015 del Banco Mundial. Se encuentra que la persistencia de las políticas industriales y gran vinculación al comercio internacional explican parte importante de los resultados asiáticos. Una recuperación de dichas políticas en Suramérica podría ayudar a activar la dinámica económica que no ofrece la exportación de recursos naturales.

Palabras clave: Latinoamérica, Pacífico suramericano, Consenso de Washington, Consenso de Beijing, política industrial, exportación de materias primas.

Códigos JEL: P51, O14, O25, O47, O5, O53, O54. 


\section{Abstract}

The present work confronts the industrial policies followed by the South American nations with those of the Southeast Asian countries, and states that the influence of the Washington Consensus on the former allowed to disrupt their industrial development, while the type of economic development in Asia has been more successful, framed in recent decades in what is known as the Beijing Consensus. A comparative study is made of the evolution of different economic and social indicators of the South American nations, as well as of Malaysia, Thailand and Vietnam, using United Nations-Comtrade trade data and World Bank World Development Report 2015 indicators. It is found that the persistence of industrial policies and the link to international trade explain an important part of the Asian results. A recovery of these policies in South America could help to activate the economic dynamics offered by the export of natural resources.

Keywords: Latin America, South American Pacific, Washington Consensus, Beijing Consensus, industrial policy, export of raw materials. 


\section{Resumo}

Este artigo faz uma comparação entre as políticas industriais de Nações sul-americanas Vs. Países do Sudeste Asiático, sugerindo que a influência do "Consenso de Washington" no primeiro permitiu perturbar seu desenvolvimento industrial, enquanto o tipo de desenvolvimento econômico $\mathrm{Na}$ Ásia, tem sido mais bem sucedido, enquadrado nas últimas décadas no que é conhecido como o "Consenso de Pequim". Para fazer um estudo comparativo da evolução de diferentes indicadores econômicos e sociais das nações sul-americanas, bem como Malásia, Tailândia e Vietnam é realizada, utilizando dados do comércio da Nações Unidas -Comtrade e indicadores do Relatório de Desenvolvimento Mundial 2015, Banco Mundial . Verificou-se que a persistência de políticas industriais e um forte vínculo com o comércio internacional explicam uma parte importante dos resultados asiáticos. A recuperação dessas políticas na América do Sul poderia ajudar a recuperar a dinâmica econômica que a exportação de recursos naturais não oferece.

Palavras-chave: América Latina, Pacífico Sul Americano, Consenso de Washington, Consenso de Pequim, Política industrial, Exportação matérias-primas. 


\section{INTRODUCCIÓN}

Las naciones del Este y Sur del Asia cuentan con historias milenarias, donde los reinos de China e India - entre otros - lograron grandes desarrollos sociales, económicos, políticos y tecnológicos, integrando en diferentes períodos sus flujos comerciales a diferentes naciones del área (Walter, 2006). Su relación con los pueblos europeos a partir de la llegada de las naves portuguesas en el siglo XVI se intensificó con el posterior arribo de las compañías comerciales holandesas, inglesas, francesas, españolas y alemanas, que descubrieron productos como sedas, especies, metales preciosos, tejidos de algodón, artículos de papel, de pólvora y otros que les permitieron amplias ganancias comerciales, y que profundizaron el comercio de tipo mercantilista ${ }^{1}$ y evolucionaron con los siglos hacia una delicada dependencia política.

Los poderes europeos colonizaron amplias zonas de India desde principios del siglo XVIII, consolidadas con la toma de Hong Kong por los británicos en 1842 (Walter, 2006, p. 163), logrando con presiones políticas y militares amplias concesiones comerciales, legalización del lucrativo y lesivo comercio del opio, derechos a emisión de moneda, entre otros. Durante estos siglos, los estados europeos en expansión se fortalecieron en muchas

\footnotetext{
${ }^{1}$ El mercantilismo tuvo por lema: “Vender sistemáticamente más de lo que se compra, para alcanzar balanzas comerciales positivas".
} 
esferas, crearon y desarrollaron la Revolución Industrial, se globalizaron y tomaron territorios en todo el planeta, mientras los viejos reinos asiáticos decayeron y su potencia económica se quebró. La descolonización tardó hasta pasada la Segunda Guerra Mundial, cuando India logró su independencia de Inglaterra en 1947, China, en 1949, y otras naciones vecinas la obtuvieron sucesivamente. El costo colonial fue inmenso: los otrora ricos reinos asiáticos eran ahora países independientes pero con escasas industrias, muy poblados y pobres, que debieron emprender poderosas políticas para mejorar sus condiciones de vida y recuperar las posiciones perdidas.

Importante aporte en este esfuerzo constituyeron las políticas industriales y de desarrollo que siguieron los diferentes gobiernos, estimulados por el saludable apoyo de las recientemente creadas "Comisiones Económicas" de las Naciones Unidas: en 1947 se creó, con sede en Shanghai, la Comisión Económica para el Asia y el Lejano Oriente, que fue trasladada a Bangkok (Tailandia) en 1949. En 1961, la ONU lanzó su primera "década del desarrollo económico" (Mahtaney, 2007, p. 2) y a pesar de las dificultades económicas, de la Guerra Fría y las conmociones internas en muchas naciones, los planes de desarrollo fundados en el estímulo a la creación de industrias fueron sistemáticamente lanzados, apoyados por políticas estatales de protección arancelaria y comercial, de apertura a la inversión extranjera directa y exportadora hacia los países desarrollados, logrando las naciones capitalistas de esta zona del globo estructurar poco a poco fuertes corredores industriales que se entrelazaron con los mercados mundiales, acrecentaron el nivel de vida de cientos de millones de sus habitantes y consolidaron sus desarrollos económicos.

Por su parte, China acogió un tipo de desarrollo socialista que, con el apoyo de la entonces Unión Soviética, además de unificar políticamente el país y emprender una inmensa campaña de educación, invirtió masivamente en infraestructura industrial y productiva. Con su reforma postmaoista de 1979 hacia la apertura al mundo, China adoptó ciertos patrones capitalistas de producción con la creación de "zonas especiales de producción", las cuales fueron rápidamente reproducidas a lo largo de sus áreas costeras, asimilaron tecnologías de firmas transnacionales y multiplicaron sus soportes industriales y comerciales, llegando a constituirse a principios del siglo XXI en el principal exportador de bienes industriales del globo: "la fábrica del mundo". Si bien el desarrollo de China y algunas otras naciones socialistas del Asia fue políticamente muy diferente al de sus vecinos capitalistas, ambos bloques privilegiaron el desarrollo de fuertes políticas industriales, integraron masivamente sus poblaciones al 
estudio y al trabajo, y se orientaron claramente a la exportación de bienes industriales al mundo desarrollado, y luego a todo el globo.

En América Latina, la historia fue diferente: mientras a principios del siglo XIX en Asia se profundizaba el colonialismo europeo, en América Latina se terminaban los dominios español y portugués. Sin embargo, las tradiciones coloniales de exportar materias primas a Europa continuaron y no se desarrollaron sectores industriales de importancia sino hasta principios del siglo $\mathrm{XX}$ en países como Argentina, Brasil y México, o posterior a la Segunda Guerra Mundial en Colombia, Perú y otros países (Astori, 1980); precisamente siguiendo políticas industriales y proteccionistas recomendadas por las Comisiones Económicas de las Naciones Unidas, relativamente similares a las practicadas en Asia. Sin embargo, a diferencia de la industrialización "dependiente" o sin autonomía respecto de las empresas transnacionales - planteada por Astori para Latinoamérica-, el proceso industrial del Asia sí ha logrado mayor autonomía, debido a la confluencia de otras fuerzas locales impulsadas por los Estados, tales como educación masiva, infraestructura, desarrollos tecnológicos, visiones nacionales, que se sumaron a la inversión y tecnología extranjeras, logrando "endogeneizar" partes claves de los procesos industriales practicados.

En la primera parte, y con el fin de establecer el tipo de estructuras sociales y productivas que conforman los países del Pacífico suramericano, se delinearán algunas de sus características y se compararán con las de países tropicales del Sureste Asiático, relativamente similares en términos de ingresos, población e indicadores sociales, tales como Indonesia y Tailandia. En la segunda parte se analizarán diversos indicadores del comercio del Pacífico suramericano con China y Asia, el cual registra desde principios de siglo crecimientos impactantes y centrados en la exportación de commodities a China, comercio sujeto a la tradicional variabilidad del precio internacional de las materias primas, con incidencia importante en los ingresos de los Estados suramericanos. En la tercera parte se confrontarán, a través de la evolución de indicadores del grado de apertura al comercio exterior, industrialización, inversión, innovación y financiación, los resultados que muestran los modelos de desarrollo predominantes a ambos lados del Pacífico. En la cuarta parte se consideran los principales fundamentos de los "consensos" de Washington y Beijing, con énfasis en las implicaciones

${ }^{2}$ Aunque no ha sido recogido por la RAE, utilizamos aquí el verbo "endogeneizar" para expresar la acción referida a "endógeno", sustantivo que según la RAE (2) significa "que se origina en virtud de causas internas". 
de su aplicación en las dos áreas del globo, determinadas en buena medida por la presencia o ausencia de políticas industriales e internacionalización, y reforzadas por los ciclos de precios internacionales de las materias primas. A continuación y para establecer un paralelo entre el desarrollo reciente de países de ambas áreas del planeta, se presentarán diferentes indicadores del desarrollo social y económico de estas naciones. En último término se relacionan varias conclusiones.

\section{METODOLOGÍA E HIPÓTESIS}

El presente estudio se concentrará en establecer la evolución y las implicaciones del tipo de relación comercial que se está dando entre los cuatro países del Pacífico suramericano (Chile, Perú, Ecuador y Colombia) con el Asia, y particularmente con China, y la incidencia que han tenido y seguramente seguirán teniendo las políticas de los llamados "consensos" de Washington y Beijing. Se realizará un estudio comparativo de la evolución de diferentes indicadores económicos y sociales de las naciones suramericanas, así como de Malasia y Tailandia - y según la disponibilidad de información, de Viet Nam, utilizando datos de comercio de las Naciones Unidas-Comtrade e indicadores del World Development Report 2015 del Banco Mundial一.
Hipótesis de trabajo: las políticas industriales seguidas en diferentes grados por las naciones capitalistas en desarrollo - tanto de Suramérica como del Este y Sur del Asia - con posterioridad a la Segunda Guerra Mundial, fueron desvertebradas en Suramérica desde la implantación de las políticas recomendadas por el Consenso de Washington. De manera diferente, pudieron continuar siendo aplicadas y adaptadas a las situaciones de los países del Asia, permitiendo a estas naciones perseverar en la senda industrial y ampliar la vinculación a los mercados internacionales, según las definiciones políticas adoptadas a partir de sus procesos de descolonización de la postguerra.

\section{ALGUNOS INDICADORES SOCIALES Y ECONÓMICOS}

A pesar de las semejanzas culturales y económicas que unen a las naciones del Pacífico suramericano, también tienen algunas importantes diferencias en su historia, en sus grados de desarrollo, especialmente claras para Chile, país que junto con los otros del Cono Sur, presentó durante el siglo $\mathrm{XX}$ indicadores sociales y económicos sensiblemente mejores que sus vecinos del norte. Se señalan a continuación algunos indicadores presentados en el World Development Report 2015 (Banco Mundial, 2016): 
Tasa de desnutrición infantil (porcentaje de niños menores de 5 años): tomando como punto de inicio los indicadores reportados por las autoridades chilenas desde 1991, menos del $1 \%$ de sus infantes habrían presentado desnutrición, expresada como un bajo peso para su edad. Colombia reportaba en 1995 el 6,3\% de niños con este tipo de desnutrición, la cual se habría ido reduciendo hasta el 3,4\% en su último reporte del 2010. Ecuador y Perú informaron de niveles mayores al $10 \%$ en los años 90 , que habrían disminuido gradualmente al $6,2 \%$ y $5,1 \%$ respectivamente a mediados de los años 2000, observándose mejoramientos continuos en todos los países.

Índice de pobreza: (porcentaje de población con ingresos menores a USD 2.oo/día de poder adquisitivo paritario $^{3}$ ): desde principios de los años 90, Chile exhibe este indicador cobijando a menos del $3 \%$ de su población, mientras que Perú, Ecuador y Colombia presentaron en esos años porcentajes sustancialmente mayores, entre el 11 y el $19 \%$ del total de sus habitantes, los cuales fueron reduciéndose hasta niveles del 4,1\% para Ecuador y Perú en 2010, y del 6,8 \% para Colombia. Chile, en cambio, logró disminuir esta población pobre al $1 \%$ en 2010. Los mayores indicadores de pobreza se dan en las áreas rurales de los países, incluidos los países asiáticos que se comparan en este estudio.

\section{Cobertura bruta de educación ter-} ciaria: este indicador se refiere al porcentaje de la población de cada país que accede a la educación postsecundaria. Todos los países del mundo -y también los suramericanos- han ampliado significativamente el acceso de su población a la universidad y a otros tipos de educación tecnológica terciaria en décadas recientes (ver Figura 1). En el caso de Perú, Ecuador y Colombia, a principios de la década del 2000 reportaron que entre el 20 y $30 \%$ de sus habitantes asistían a cursos postsecundarios, mientras que hacia 2010 habrían involucrado a algo más del $40 \%$. Estas coberturas son relativamente semejantes a las reportadas por Tailandia y Malasia. Chile, por su parte, habría capacitado muchos más ciudadanos, alcanzado el $70 \%$. Este indicador solo expresa cobertura bruta y no evalúa ni la calidad ni la duración de los cursos ofrecidos.

\footnotetext{
${ }^{3}$ El poder adquisitivo paritario -PAP- (Purchasing Parity Power -PPP en inglés) se refiere a un reajuste hacia arriba del poder adquisitivo nominal de los ingresos de los países en desarrollo, que se calcula para compensar el hecho de que los salarios son menores que en los países desarrollados y, por tanto, muchos productos locales tienen un menor precio que los internacionales. Los ingresos locales medidos en PAP comprarían entonces más que lo indicado por la tasa de cambio. EI PAP de Estados Unidos se considera igual a uno, es decir, no se reajusta.
} 


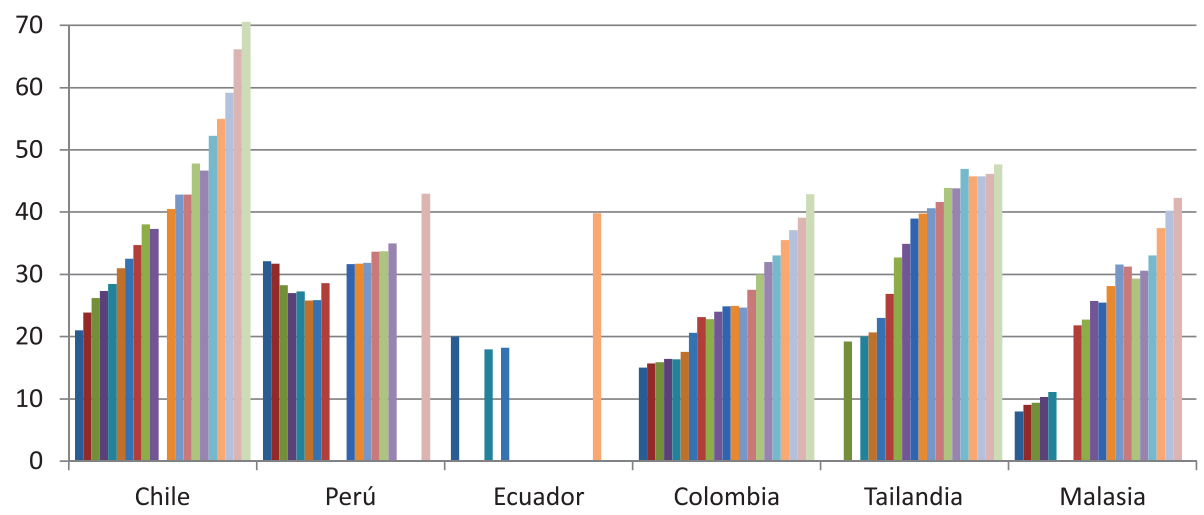

Figura 1. Cobertura bruta de educación terciaria 1991-2011 (porcentaje población).

Fuente: World Development Report 2015 Banco Mundial (2016).

Consumo per cápita de energía eléctrica $(\mathrm{kWh}$ por persona/año): el acceso a la energía eléctrica no solo permite un mejor nivel de vida de la población, sino que posibilita mayor utilización de herramientas y aparatos que suben la productividad de los trabajadores $\mathrm{y}$, por tanto, del país. A principios de los años 90, Chile casi duplicaba los kilovatios hora/año usados en Colombia, y triplicaba los del Perú y Ecuador. Todos estos países han continuado instalando plantas de generación eléctrica y hacia 2011 habían poco más que duplicado su capacidad de generación per cápita, logrando Chile casi triplicar el monto de electricidad usada por sus vecinos: Chile $3.568 \mathrm{kWh} / \mathrm{año} /$ pc, Perú 1.268, Ecuador 1.192 y Colombia 1.123 (ver Figura 2). También se muestra el consumo en países del Sudeste asiático como Tailandia y Malasia, los cuales a principios de los 90 consumían cantidades de electricidad per cápita similares a sus pares suramericanos, pero experimentaron tasas más rápidas de crecimiento posteriormente, debido a sus políticas expresas de inversión en infraestructura y transformación industrial: 


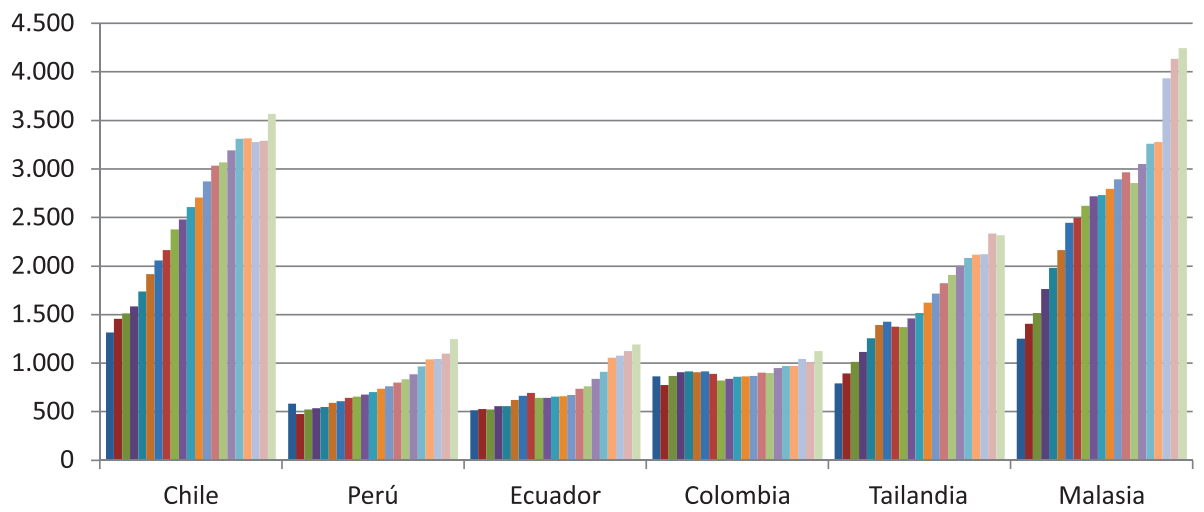

Figura 2. Consumo per cápita de energía eléctrica 1991-2011 (kWh/año).

Fuente: World Development Report 2015 Banco Mundial (2016).

Ingreso per cápita: los anteriores indicadores revelan que Chile ha conseguido un mejor nivel de vida, ingresos y productividad que sus vecinos del Pacífico suramericano. Un indicador que puede resumir dicha condición estructural e histórica es el "ingreso nacional per cápita", expresado en la Figura 3 en dólares de los Estados Unidos (con poder adquisitivo constante del año 2005). El ingreso per cápita chileno hacia 1970 era solo un poco mayor que el del Perú, pero superaba en cerca del $50 \%$ los de Ecuador y Colombia, países que a su vez superaban el ingreso per cápita de Malasia, y más aún el de Tailandia. Sin embargo, los agudos conflictos sociales y políticos de Chile en los años
70 y del Perú hasta los 90, así como la "década perdida" de los 80 por la crisis de la deuda externa latinoamericana, frenaron el crecimiento de sus ingresos nacionales y limitaron los del Ecuador y Colombia ${ }^{4}$. Se aprecia en la Figura 3 cómo Chile recuperó su ritmo de crecimiento en la segunda mitad de los años 80 y presenta actualmente los mayores ingresos per cápita del grupo. Las naciones asiáticas tuvieron ingresos per cápita más bajos que las suramericanas en los años 70 , pero su rápido crecimiento les permitió reducir distancias y, a la fecha, Malasia supera a Perú, Ecuador y Colombia, mientras que el ingreso per cápita de Tailandia se les acerca.

\footnotetext{
${ }^{4}$ Chile tuvo un golpe militar en 1973, que ocasionó gran disrupción institucional y política (Birle, 2013); Perú vivió la guerra interna de guerrillas entre los años 1980-90 (Lavaux \& Ochoa, 2010); en Ecuador se terminaron los gobiernos militares en 1980 y continuó viviendo gran inestabilidad institucional (Ulloa, 2006), mientras que Colombia ha mantenido un largo conflicto armado interno, afortunadamente en proceso de superación. Los conflictos étnicos y políticos que se presentaron en Malasia como resultado de la política migratoria colonial inglesa fueron exitosamente manejados con estrategias como la "Nueva Política Económica" a partir de 1971 (Tan, 2012) y la construcción de una "identidad nacional pluriétnica".
} 


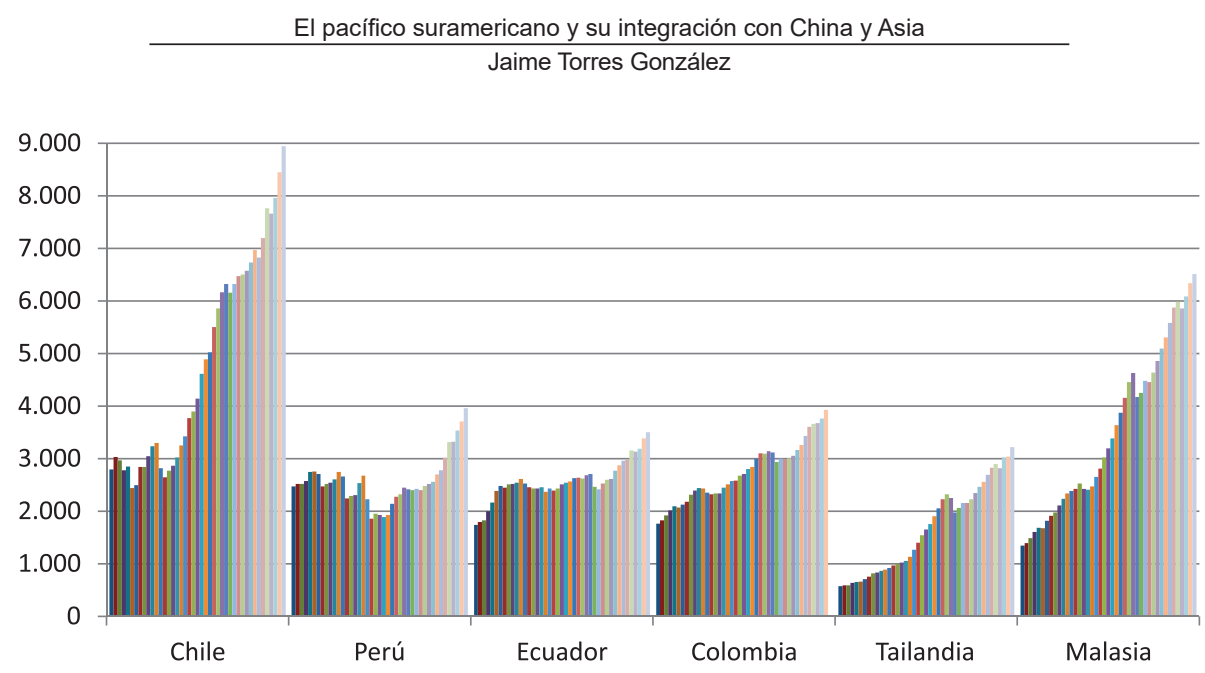

Figura 3. Ingreso nacional per cápita 1970-2012 (USD constante 2005).

Fuente: World Development Report 2015 Banco Mundial (2016).

\section{LA RECIENTE VINCULACIÓN ECONÓMICA DE SURAMÉRI- CA CON LA REPÚBLICA PO- PULAR CHINA Y EL ASIA}

Aunque los primeros migrantes chinos que masivamente llegaron a Suramérica lo hicieron con destino al Perú desde 1849 (Chuhue, Na \& Coello, 2012), donde fueron contratados para laborar en cultivos de caña de azúcar, algodón y otras actividades en la costa peruana, en virtud de la crisis laboral presentada por la abolición de la esclavitud de los naturales africanos, la integración comercial entre los países del Pacífico suramericano y la China solo adquiere amplias proporciones en el siglo XXI. En décadas anteriores solo era representativo el comercio con Japón. Es a través de la exportación de minerales como cobre, estaño, plomo, hierro, así como energéticos (petróleo crudo), que el comercio internacional entre las dos áreas alcanza cifras representativas y se abren rutas navieras estables. Las exportaciones de los cuatro países suramericanos a la Cuenca Pacífica Asiática totalizaron USD 7358 millones en el año 2000, y se multiplicaron 8.3 veces para el 2014, cuando ascendieron a USD 60798 millones, lo que representa con creces el mayor crecimiento en relación con otras regiones del globo.

La muy rápida inserción de China en el comercio internacional a fines del siglo $\mathrm{XX}$, acrecentada a partir de su vinculación a la OMC (Organización Mundial del Comercio) en 2001, unida a su impresionante crecimiento económico cercano al $10 \%$ anual durante 30 años (Torres, 2016), propició una 
creciente demanda de materias primas que tuvo efectos globales: los precios internacionales de dichos commodities aumentaron velozmente y favorecieron a los países y a las empresas transnacionales que los explotaban. De acuerdo con la Comisión Económica para América Latina (Cepal):

El elevado volumen de las importaciones desde China modificó la estructura del mercado internacional: en 2000 las importaciones de [mineral de hierro de] China correspondían a 70 millones de toneladas métricas, es decir el $14,4 \%$ del volumen y el $14,3 \%$ del valor de las importaciones mundiales, y en 2014 habían llegado a 932 millones de toneladas métricas, equivalentes al $68,4 \%$ en volumen y al $64,6 \%$ en valor del total mundial. Al mismo tiempo, han perdido peso los países con mayor consumo histórico: Alemania, la República de Corea y, especialmente el Japón, que hasta 2001 fue el principal importador de mineral de hierro del mundo. Un fenómeno parecido se ha verificado en los casos del concentrado de cobre (China pasó del $12,6 \%$ en 2000 al $40,1 \%$ en 2014). Las importaciones de China comenzaron a crecer en 1995 y para 2000 ya habían superado a la mayoría de los principales importadores del mundo, como Alemania, España, la India y la República de Corea. En 2009 China desplazó al Japón, cuya participación declinó de forma constante... El marcado aumento de las importaciones de alúmina y bauxita determinó que China superara la cuota de los Estados Unidos en el mercado internacional [de aluminio] a partir de 2007 y se consolidara como el principal importador, con una participación en torno al $40 \%$ del mercado. (Cepal, 2016, pp. 85-87), (negrillas fuera de texto)

La conversión de China en la "fábrica del mundo", su impresionante desempeño interno y exportador, que la hicieron importar enormes cantidades de materias primas, estimuló el "boom de los commodities", espectacular incremento que indujo una gran alza en volumen y valor de las exportaciones suramericanas a principios de la pasada década, y concentró sus ventas en materias primas minerales y energéticas. En la Figura 4 se aprecian las exportaciones de las naciones del Pacífico suramericano a todo el mundo, donde se puede observar el rápido incremento anual, especialmente del año 2004 al 2012, cuando los precios internacionales crecieron velozmente. Para los casos de Chile, Perú y Colombia se observa también el comienzo de la declinación de ventas externas en 2012-2013, tendencia que ha continuado en 2015-2016, en lo que se denomina "el fin del ciclo alcista de los commodities". 


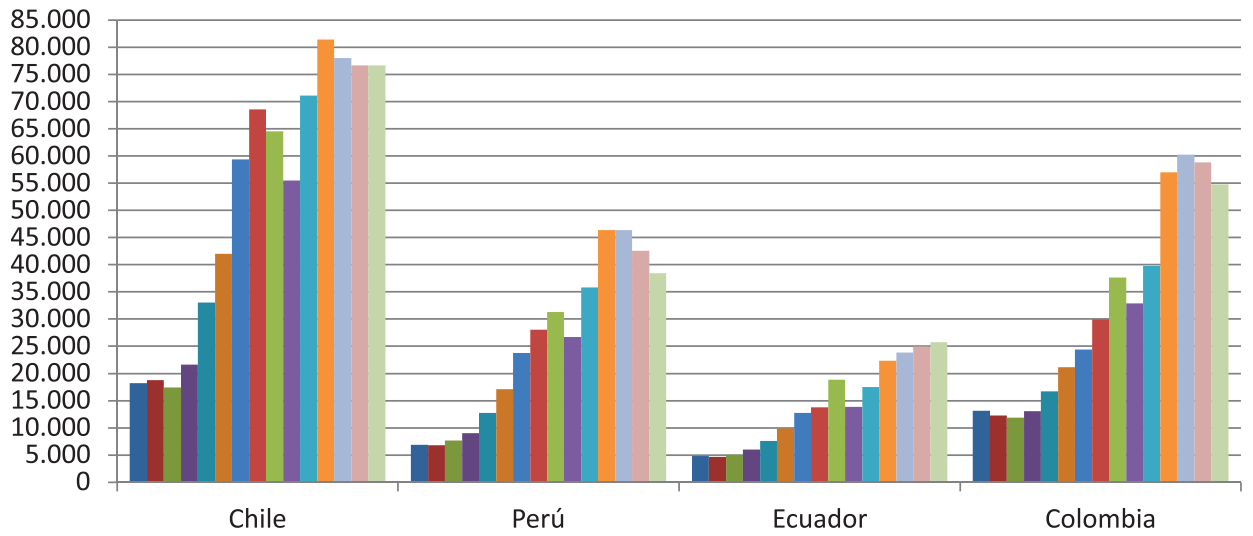

Figura 4. Total exportaciones de Chile, Perú, Ecuador y Colombia al mundo 2000-14 (USD mill.)

Fuente: cálculos propios con base de datos de Comtrade.

Al analizar la Figura 5, se hace evidente la gran relación comercial que ha desarrollado Chile con el Asia, y crecientemente con China, áreas que se han convertido en su principal mercado global y explican cerca de la mitad del total de sus exportaciones. El cobre, en bruto (mineral concentrado) y refinado, comanda sus envíos con una participación en aproximadamente el $75 \%$ del total. De manera similar, para Perú las exportaciones de cobre y otros minerales a China y el Asia ya significan algo más de la cuarta parte del total de sus ventas externas, con una participación de cerca del $80 \%$ del total exportado al Pacífico.
Las exportaciones de Colombia están muy centradas en el petróleo crudo (84\% del total a la Cuenca Pacífica en 2014), las que le permitieron expandir su facturación y disminuir el amplio déficit comercial con China, aunque disminuyeron rápidamente en 20152016. Para Ecuador, la ligazón comercial con el Asia es todavía menor, pero sus ventas de petróleo han oscilado entre el 30 y el $70 \%$ del total en períodos recientes. En general, se aprecia en todos los países una muy elevada concentración en exportación de materias primas al Asia, siendo China quien explica los elevados crecimientos recientes. 


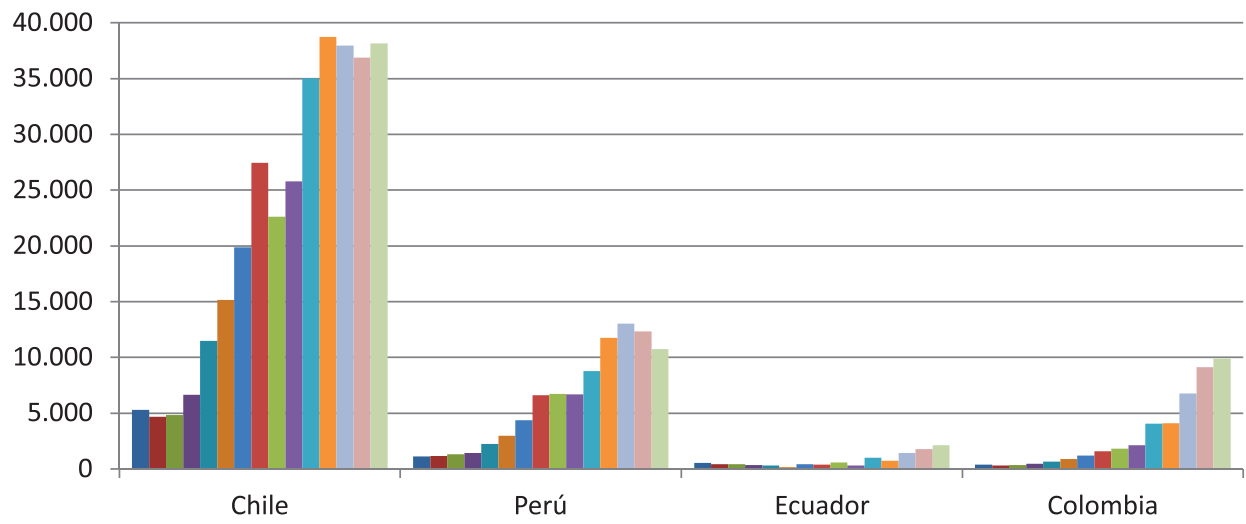

Figura 5. Total exportaciones de Chile, Perú, Ecuador y Colombia a la Cuenca Pacífica 2000-2014 (millones de USD).

Fuente: cálculos propios con base de datos de Comtrade.

\section{Orientación de las exportaciones al Asia}

Aprovechando la favorable dotación natural minera y petrolera de los países del Pacífico suramericano, los coyunturalmente rentables precios internacionales de las materias primas y la presencia de pocas manufacturas exportables ${ }^{5}$ a los mercados orientales, se produjo un importante viraje en la dirección del comercio internacional, colocando crecientemente sus producciones de bienes primarios especialmente en China, país que remplazó al Japón como mayor importador asiático. En las gráficas siguientes se aprecia cómo han variado las participaciones porcentuales de los diez primeros productos de exportación de Chile, Perú, Ecuador y Colombia (promedio trianual de 1992-1994; 2002-2004, y 2012-2014) a los países de la Cuenca del Pacífico:

\footnotetext{
${ }^{5}$ La producción de manufacturas de estas naciones suramericanas se ha dirigido fundamentalmente a atender sus mercados internos, a exportar entre ellas y hacia otros vecinos latinoamericanos, pero no presenta mayor competitividad para abastecer la demanda asiática. Las exportaciones manufactureras de Colombia, que llegaron a un significativo 40 \% del total exportado a fines de los años 90 (Figura 11) (Banco Mundial, 2016), empezaron a caer rápidamente desde 2008 , en un proceso muy vinculado a la revaluación del peso colombiano.
} 


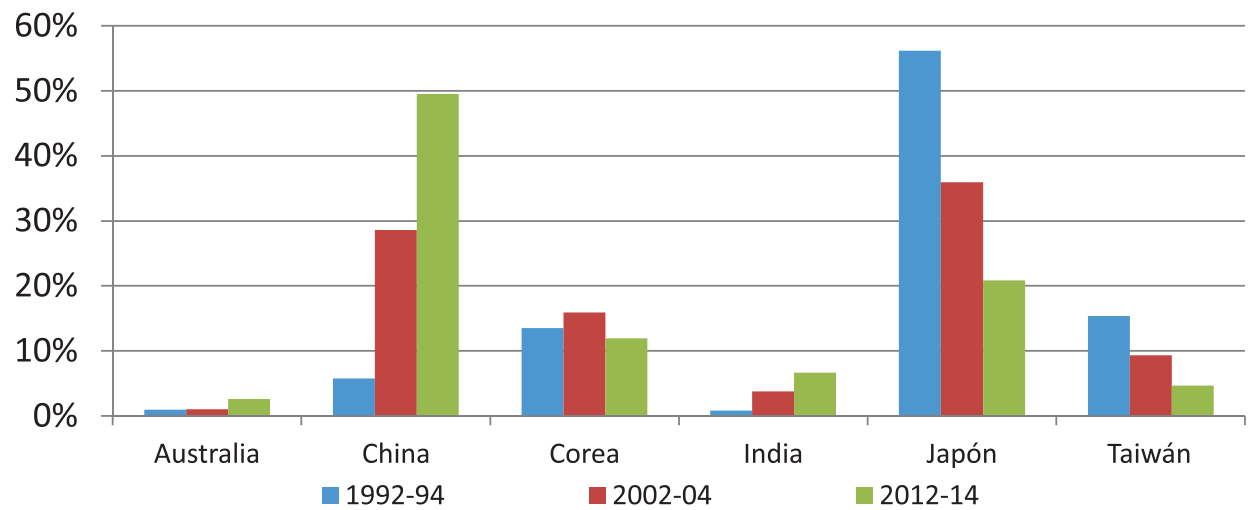

Figura 6. Chile destino del valor exportado a Cuenca Pacífica (porcentaje Top 10 Prod.)

Fuente: cálculos propios con base de datos de Comtrade.

El comportamiento de las exportaciones chilenas al Japón es inverso al de la China en el período considerado: la participación de sus exportaciones al primero decrecieron (Figura 6), mientras que a China aumentaron rápidamente. Sin embargo, no se redujeron en valor, pues han oscilado hacia arriba entre USD seis mil y ocho mil millones al Japón los últimos ocho años, incluyendo además del cobre (USD 4 964 millones promedio 2012-2014), un importante volumen de pescado (cerca de USD 1000 millones promedio los últimos tres años). No obstante, su participación ha descendido en virtud del muy rápido ascenso de
China, que ya sobrepasó al Japón en 2007 como comprador de Chile, y en lo sucesivo continuó creciendo rápidamente hasta contabilizar un promedio de USD 18672 millones entre 2012 y 2014. Se observa que a pesar del declive de los precios del cobre desde 2012, el valor adquirido por China continuó estable hasta 2014 debido al aumento del volumen importado. Otros grandes compradores del cobre chileno en Asia, según promedios trianuales 2012-2014, fueron: Corea USD 3.194 millones, India USD 2267 millones y Taiwán USD 1358 millones, países que lo utilizan en su amplia fabricación de equipo eléctrico y electrónico. 


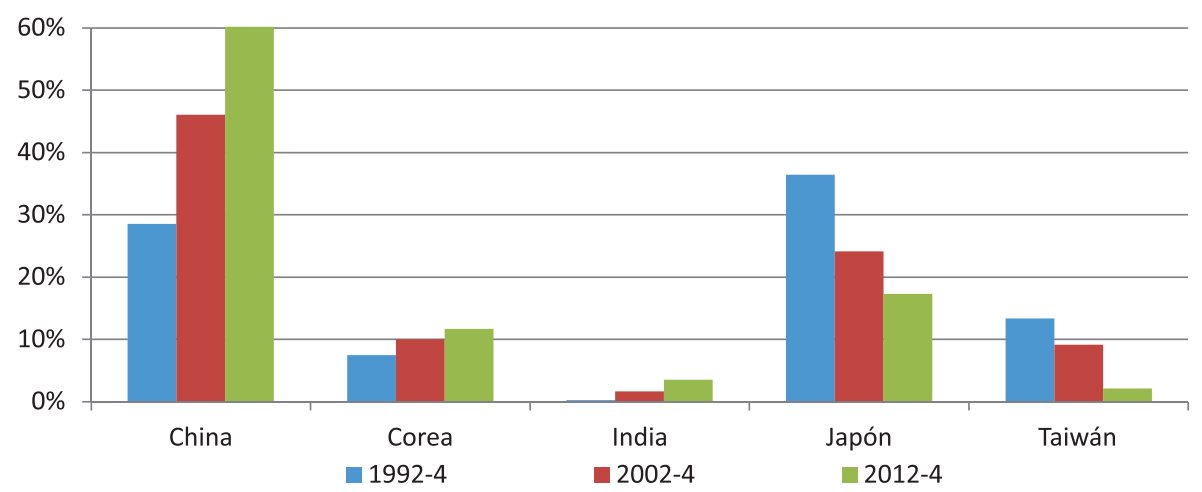

Figura 7. Perú participación valor exportado a Cuenca Pacífica (porcentaje Top 10 Prod.)

Fuente: cálculos propios con base de datos de Comtrade.

El Perú exportó USD 1142 millo- primas minerales, como el zinc, plones al Asia en el año 2000, cifra que mo, hierro, oro y mineral de metales se multiplicó 9.4 veces y ascendió a USD 10769 millones en 2014. De manera similar a Chile, su producto estrella de exportación al Asia es el cobre. Pero, además, presentó una oferta diversificada de otras materias preciosos, así como cantidades moderadas de petróleo y gas. El destino principal del Perú (Figura 7) es China (entre 60 y $65 \%$ del total), seguida por Japón, Corea, Taiwán e India.

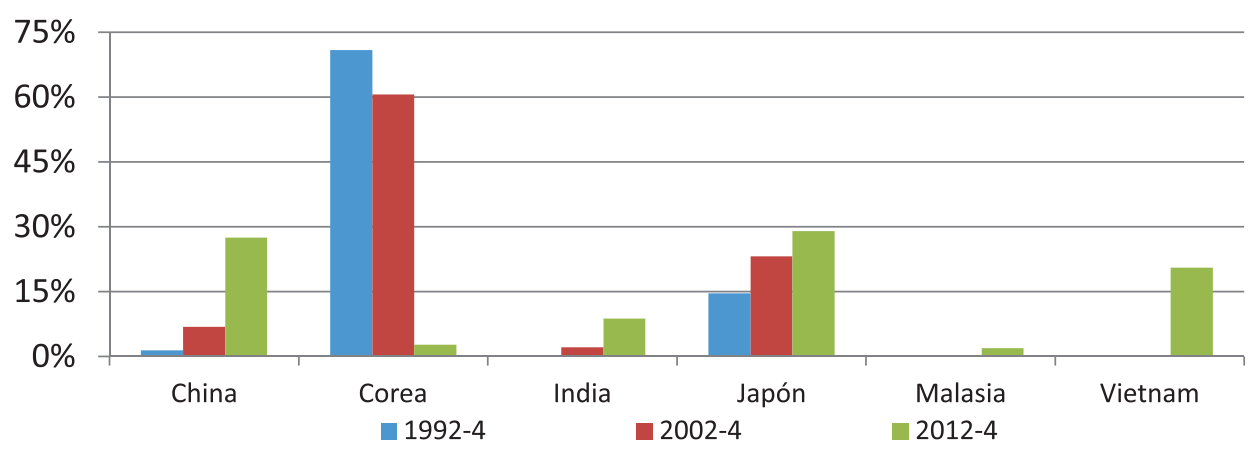

Figura 8. Ecuador participación valor exportado a Cuenca Pacífica (porcentaje Top 10 Prod.)

Fuente: cálculos propios con base en datos de Comtrade. 
Las exportaciones ecuatorianas al Asia han crecido cuatro veces desde el año 2000, pero muestran un patrón discontinuo, típico de la apertura de nuevos mercados en proceso de consolidación. Su principal producto ha sido el petróleo crudo, inicialmente con destino a Corea, pero remplazado recientemente por Japón y China (Figura 8). Solo en los últimos períodos ha abierto otra nueva y muy dinámica línea de camarones y frutos del mar con Viet Nam.

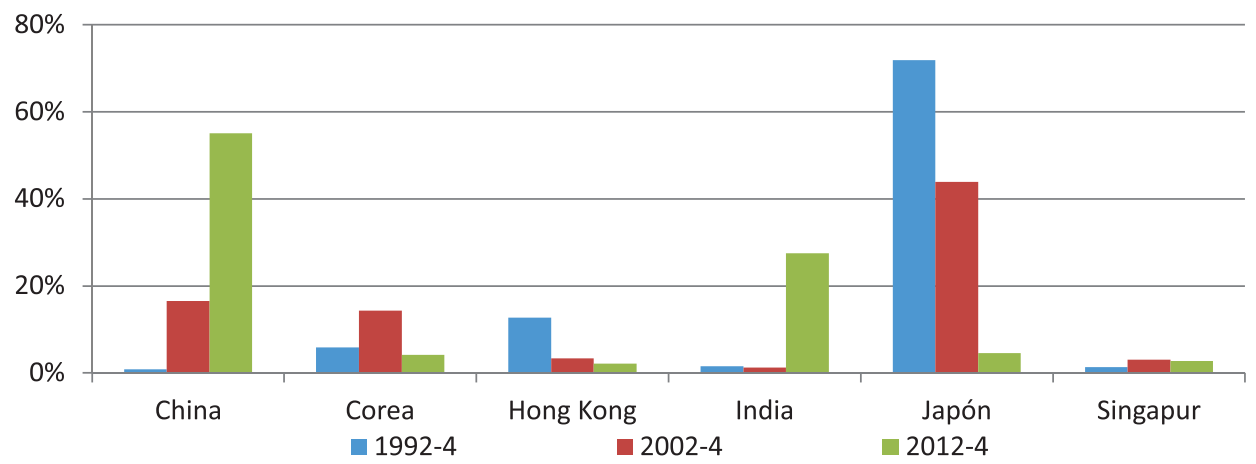

Figura 9. Colombia participación valor exportado a Cuenca Pacífica (porcentaje Top 10 Prod.)

Fuente: cálculos propios con base en datos de Comtrade.

Colombia es un "recién llegado" al comercio con el Asia. En el año 2000 solamente exportaba USD 378 millones, que ascendieron a USD 9918 millones en 2014, es decir, creció 26 veces. Inicialmente vendía café al Asia, más ferroníquel al Japón, China, Corea y Taiwán. En 2008 inició las exportaciones de petróleo crudo y sus derivados pesados, concentrándose en China,
India y Singapur. Para 2014, el $90 \%$ de las ventas a China - su principal cliente- fue de petróleo. Igualmente con India y Singapur el producto estrella es el petróleo crudo. La canasta exportadora colombiana es muy poco diversificada, y los valores absolutos exportados de petróleo a China e India han caído después del $2014^{6}$.

\footnotetext{
${ }^{6}$ Es interesante observar cómo parte de la búsqueda de empresarios colombianos por nuevos mercados en el Asia se motivó en el radical descenso de las exportaciones a Venezuela a partir del año 2008 por razones políticas, debido a un bombardeo de las fuerzas armadas colombianas a un campamento de guerrilleros colombianos apostados en el Ecuador, hecho duramente refutado por el gobierno ecuatoriano como una violación a su integridad territorial, postura que contó con el resuelto respaldo del gobierno venezolano, motivando el desplome de las exportaciones colombianas a este país, que habían sumado cerca de US\$6.000 millones en 2007, la mayoría siendo productos industriales. Una real diversificación de exportaciones colombianas al Asia no se produjo, ya que se concentraron en ventas de petróleo crudo, las cuales decayeron en 2015/16.
} 
Fin del ciclo de buenos precios de las materias primas y la caída de las rentas de recursos naturales

El ciclo de precios favorable que se presentó con las materias primas al inicio de la presente centuria ha mostrado su declinación desde 2012 para el cobre, en 2014 para el petróleo, y a fines del 2015 prácticamente todas las materias primas exportadas en el mundo mostraban precios a la baja: el ciclo de buenos precios internacionales de los commodities llegó a su fin. Se inició el primer ciclo de precios bajos del siglo XXI, que tendrá una duración incierta pero seguramente se prolongará por varios años, en la medida que la demanda internacional crece lentamente en Europa, Japón, los Estados Unidos, Brasil y hasta en su motor reciente (China), por reducción de su crecimiento económico y la menor dinámica exportadora. Esta "destorcida" de precios tiene importantes consecuencias en los países suramericanos del Pacífico, ocasionada por las grandes reducciones de sus ingresos en divisas, lo que implica reducción de ingresos para los gobiernos, tanto por pérdidas financieras de las empresas estatales exportadoras, como por bajos recaudos de impuestos a productos exportables (regalías) y menores pagos de impuestos a la renta de las transnacionales que explotan localmente los recursos.

En Colombia, la caída del valor de las exportaciones petroleras y carboneras está teniendo críticas consecuencias, pues significó un déficit en la cuenta corriente del país ${ }^{7}$ de USD 19489 millones en 2014 y de USD 18755 millones en 2015 (Banco de la República, 2016), que representaron un déficit cercano al $7 \%$ del producto interno bruto. Este déficit indujo una radical devaluación del peso colombiano respecto del USD: aproximadamente el $66 \%$ con relación a comienzos del año 2014. Con respecto a la Empresa Colombiana de Petróleos (Ecopetrol S.A.), la mayor empresa colombiana —de propiedad estatal en $87 \%$-, en su ejercicio contable de 2014, cuando hubo buenos precios internacionales del petróleo el primer semestre, reportó utilidades netas anuales por 6.3 billones de pesos colombianos ${ }^{8}$ (Ecopetrol, 2016), después de pagar un impuesto a la renta por 4.8 billones de pesos colombianos, que nutrió las arcas del Estado y le posibilitó cubrir importantes gastos. En cambio, para el año 2015, Ecopetrol registró pérdidas

\footnotetext{
${ }_{7}^{7}$ El déficit en Cuenta Corriente se origina al confrontar los ingresos (Dólares por exportación de bienes y servicios + las rentas externas recibidas) contra los Egresos (valores importados + los intereses por deuda externa + las utilidades enviadas al exterior por los inversionistas extranjeros).

${ }^{8}$ A la tasa de cambio promedio de 2014 equivalieron a USD 3.150 millones las utilidades y a USD 2.400 millones el impuesto de renta. En 2015 equivalieron a USD 1.130 millones las pérdidas y a USD 218 millones los impuestos. Un billón se computa por 12 ceros (millones de millones de pesos colombianos).
} 
por 3.1 billones de pesos colombianos, lo que disminuyó los impuestos a la renta cancelados al Estado a 0.6 billones de pesos colombianos (aprox. USD 218 millones), es decir, solo el $9 \%$ de la contribución impositiva del año anterior, caída que ha obligado al Gobierno a aumentar el endeudamiento en dólares, a recortar gastos y a hacer aprobar otra reforma fiscal para recuperar ingresos vía impuestos a su ciudadanía.

Para el caso de Chile, la empresa estatal Corporación Nacional del Cobre (Codelco S.A.), que solo pagó impuestos por USD 269 millones en 2003 (Codelco, 2003-2015), cuando los precios internacionales del cobre apenas se reactivaban, ascendió en 2006 a un máximo histórico de USD 4.565 millones de impuesto a la renta cancelado al Estado. Para los doce años transcurridos entre 2004 y 2015, la empresa pagó un impuesto a la renta por un total de USD 33069 millones (promedio anual de USD $2776 \mathrm{mi}-$ llones), siendo con amplitud la mayor aportante de ingresos fiscales de su Estado. Igualmente, Codelco produjo valores equivalentes de utilidades en ese período de buenos precios, que le permitieron invertir en tecnología y nuevos desarrollos mineros. En 2012, sus utilidades netas fueron de USD 3875 millones, que se redujeron paulatinamente hasta USD 711 millones en 2014, mientras en 2015 presentó, por primera vez en lo corrido del siglo, pérdidas contables netas por USD 2.328 millones, que implicó reducir su impuesto a la renta a solo USD 728 millones.

De acuerdo con cálculos de la Cepal (2016, p. 118), los ingresos fiscales por minería metálica para Chile y Perú entre los años 2000 y 2003 fueron del $4 \%$ y $1 \%$ del total recibido por los gobiernos, respectivamente. Para 20052008 se multiplicaron ocho veces para Chile (28.1\% del total) y diez veces para Perú (10.6 \%). Para 2010-2014 continuaron siendo muy importantes, pero rebajaron al $13.8 \%$ para Chile y $6.4 \%$ para Perú. Muchos de los logros en construcción de infraestructura, reducción de la pobreza y mejoramiento del nivel de vida de sus poblaciones, fueron posibles gracias a las inversiones en infraestructura, servicios sociales y redistribución de las rentas mineras entre la población. La destorcida de los precios internacionales hace que hoy, y hacia el futuro, se vean comprometidos dichos logros. Los ciclos al alza, seguidos durante varios años por precios a la baja, que son típicos de las materias primas, implican una significativa fragilidad para los países que concentran sus ingresos en divisas por cuenta de pocos productos exportados. Las consecuencias negativas en sus economías son palpables, y su estabilidad financiera como Estados dependerá en el futuro del desarrollo de una razonable diversificación productiva y exportadora. 


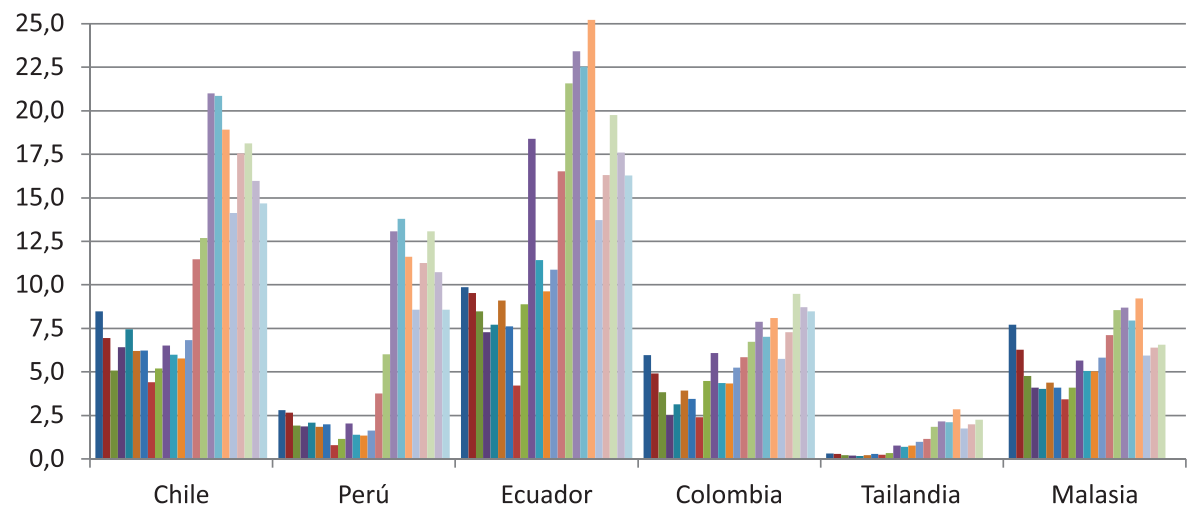

Figura 10. Participación en porcentaje de rentas mineras y petroleras en PIB 1991-2013.

Fuente: World Development Report 2015 (Banco Mundial, 2016).

En la Figura 10 se aprecia la importancia que tienen las rentas minero-energéticas para los países del Pacífico suramericano, Tailandia y Malasia. Estas superaron durante los últimos años el $10 \%$ del PIB del Perú y alcanzaron entre el 15 y $28 \%$ para Chile y Ecuador. Colombia, que tiene la economía más diversificada del grupo suramericano y produce más manufacturas, muestra las menores rentas del grupo, pero similares a Malasia que vende petróleo y gas. Tailandia aparece mucho más abajo, pues junto con las demás naciones del Sur y Este del Asia, han construido modelos de desarrollo más centrados en las capacidades industriales y dependen fundamentalmente de sus exportaciones manufacturadas.
DESARROLLO DE CAPACIDADES INDUSTRIALES Y EXPORTADORAS EN ASIA VERSUS MODELO EXPORTADOR DE MATERIAS PRIMAS EN EL PACÍFICO SURAMERICANO

En el análisis de ambas zonas del globo se pueden observar diferentes tendencias económicas que implican distintos modelos de desarrollo. Empleando los indicadores del WDR 2015 del Banco Mundial (2016) se presentan a continuación varios comportamientos de los países que muestran una clara inclinación industrial en el Asia, con amplias vinculaciones al comercio internacional de manufacturas, a diferencia del modelo primario-exportador que ha terminado primando con posterioridad al Consenso de Washington en los países suramericanos. Se asume en este estudio la conclusión de 
los investigadores Hausmann, Wang y Rodrik (2005), "What you export matters", en el sentido de que el tejido económico de un país recibe una gran influencia de sus sectores exportadores debido a que estos son fuentes de innovación y modernas prácticas empresariales. De esta manera, el modelo exportador predominante en un país tendrá fuertes implicaciones en la estructura productiva, educativa, en la regulación estatal, en los ingresos y otros comportamientos económicos claves. Dado el bajo encadenamiento productivo con otras actividades del país, que es usual en las explotaciones de materias primas porque emplean modernas tecnologías que son importadas casi en su totalidad, y porque la dirección empresarial — con pocas excepciones - es dominada por las firmas transnacionales, la actividad exportadora de commodities contribuye a generar rentas para el país (regalías e impuestos) pero a costa de dinamizar poco otras ramas de la economía.

De manera contraria, cuando las actividades exportadoras también involucran producción y exportación de manufacturas y servicios, con frecuencia iniciando con el procesamiento de sus materias primas, los países deben esforzarse para aportar infraestructura moderna, personal calificado, buen ambiente empresarial y adecuada regulación estatal, condiciones favorables que son apreciadas por los industriales locales y transnacionales para invertir y establecer complejas plataformas productivas que impulsan muchas otras actividades, estimulando desarrollos tecnológicos que crean empleo, ingresos, conocimiento y multiplican las capacidades productivas de una nación. Es decir, el tipo de desarrollo del sector exportador no es neutro, tampoco el papel que juegan las políticas de los estados nacionales, ni los tipos de tecnologías utilizados, de manera que su dirección tendrá incidencia clara en la estructura productiva de un país y la forma como se distribuyen los ingresos, las inversiones y la construcción del futuro de la nación. A continuación se presentan algunos indicadores que permiten comparar los modelos de inserción internacional de ambas regiones del globo. 


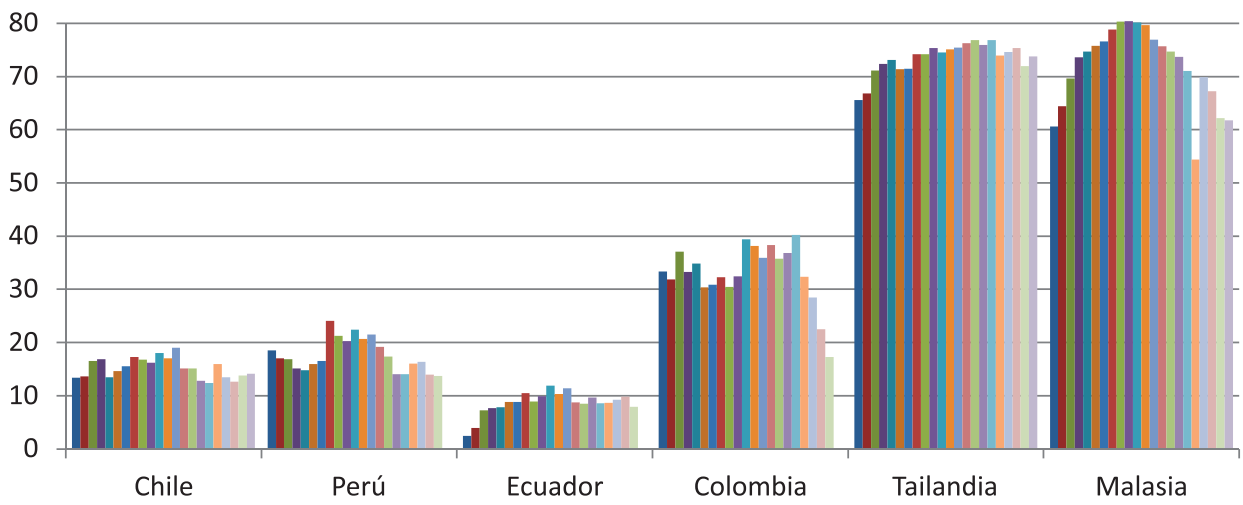

Figura 11. Porcentaje de exportación de manufacturas versus total exportaciones 1991-2012.

Fuente: World Development Report 2015 Banco Mundial (2016).

Como se puede apreciar en la Figura 11, las naciones asiáticas desarrollan capacidades manufactureras, infraestructura, alianzas industriales estratégicas con transnacionales, formación de personal cada vez más capacitado, entre otras estrategias, de manera que incursionan con fuerza en la producción y exportación de manufacturas y servicios calificados (Kim, 2001). Esto lo hacen porque han tenido una clara visión de la importancia de mantener desde el Estado activas políticas industriales, de generar masivamente empleo calificado, porque sus élites confian e invierten en las potencialidades de los habitantes de sus países, apoyando nuevos desarrollos tecnológicos y también a sus empresas privadas y estatales 9 . Son las empresas locales y transnacionales ubicadas en toda el Asia, las que más demandan las materias primas suramericanas y se benefician de la reciente caída de precios.

Destaca en la Figura 11 el vertical descenso de la participación de las exportaciones manufactureras de Colombia desde 2008, caída paralela al aumento de las exportaciones de petróleo y carbón, a la llegada de inversión extranjera para esos sectores, que han inducido la revaluación del peso. Este efecto es conocido como "enfermedad holandesa", que desestimula los ingresos de los exportadores industriales, y si su duración es prolongada, induce desinversiones en sus capacidades productivas.

\footnotetext{
${ }_{9}^{9}$ No se realiza en este estudio una comparación con indicadores de otras naciones del Este del Asia como Taiwán, Corea o China, dado que ellas han ascendido a niveles más consolidados que las del Sudeste, pero en un sendero industrial y exportador parecido.
} 


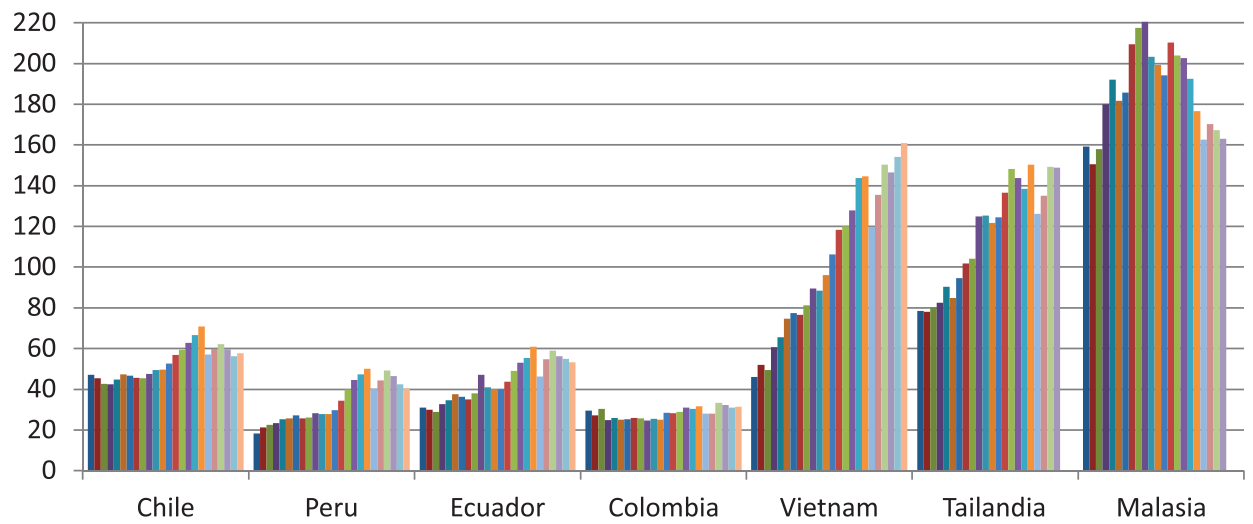

Figura 12. Porcentaje de apertura al comercio internacional 1991-2014 $(\operatorname{Imp}+\operatorname{Exp} / \mathrm{PIB})$

Fuente: World Development Report 2015 (Banco Mundial, 2016).

A pesar de los importantes volúmenes exportados por los países suramericanos, sus grados de apertura al comercio internacional son bajos globalmente, en especial cuando se los compara con la zona del planeta económica y tecnológicamente más dinámica. En la Figura 12 se observa con claridad cómo parte clave del dinamismo de las economías asiáticas se fundamenta en una alta participación en cadenas internacionales de valor, lo que les exige un constante mejoramiento de sus capacidades tecnológicas que les permita exportar manufacturas de calidad y con mayor valor agregado. Este tipo de cualificación está mucho menos presente en la exportación de materias primas minero-energéticas.
De hecho, las materias primas son parte de las cadenas internacionales de valor, pero son las partes con menor incorporación de valor local, debido a que utilizan poca mano de obra y sufren escasa transformación, y además están sujetas a fuertes e inestables ciclos de precios internacionales. Por el contrario, los productos manufacturados gozan de mayor estabilidad de precios, tienen demanda de mayor crecimiento, generan más empleo y exigen una constante cualificación de las poblaciones y empresas de sus países. Este duro proceso de industrialización y apertura lo están logrando en el Asia incluso naciones devastadas hace pocas décadas por cruentas guerras, como Viet Nam. 


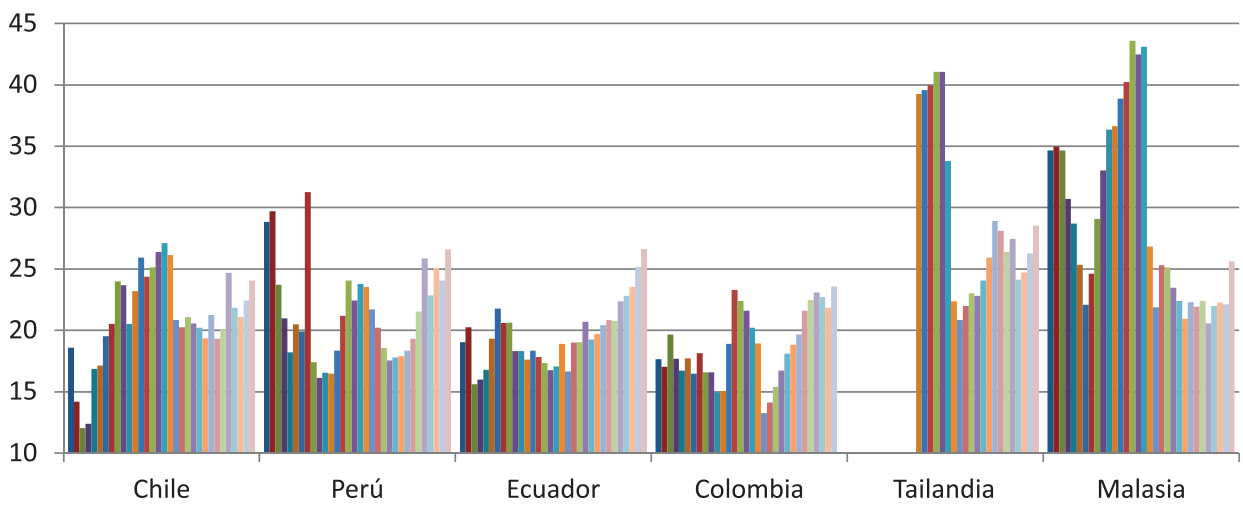

Figura 13. Formación bruta de capital fijo 1981-2012 (porcentaje del PIB)

Fuente: World Development Report 2015 (Banco Mundial, 2016).

¿Cómo logran las naciones del Asia dichos desarrollos? En la Figura 13 se aprecian las inversiones en infraestructura: vías, hospitales, escuelas, sistemas de riego, fábricas, puertos y similares (capital fijo). Los países asiáticos con rápidos avances han dedicado entre un 20 y $40 \%$ de sus ingresos anuales a construir todo tipo de infraestructura. Estas inversiones fueron usualmente mayores del $30 \%$ hasta la grave crisis de 1997. China incluso ha invertido cerca del $50 \%$ del PIB en varios períodos. En comparación, en Suramérica solo en ciertas coyunturas superamos el $20 \%$, pero además se observa inestabilidad y, por tanto, bajo compromiso para "construir nación": por ello, gran parte de las vías rurales no tienen pavimento, los puertos son pequeños, la generación de electricidad es relativamente baja, los niveles educativos son modestos, las fábricas pequeñas, las ciudades no pocas veces carecen de planeación, y con frecuencia prevalecen altos grados de corrupción. Las buenas y modernas infraestructuras construidas en el Asia durante las últimas décadas constituyen un atractivo para que se instalen nuevas empresas, muchas de ellas transnacionales líderes tecnológicas. Estas empresas no solo se concentran en explotar materias primas, sino que en conjunto con los gobiernos y socios locales, instalan grandes complejos productivos que actúan globalmente, desarrollan nuevas tecnologías y retan positivamente a las dirigencias de las naciones. 


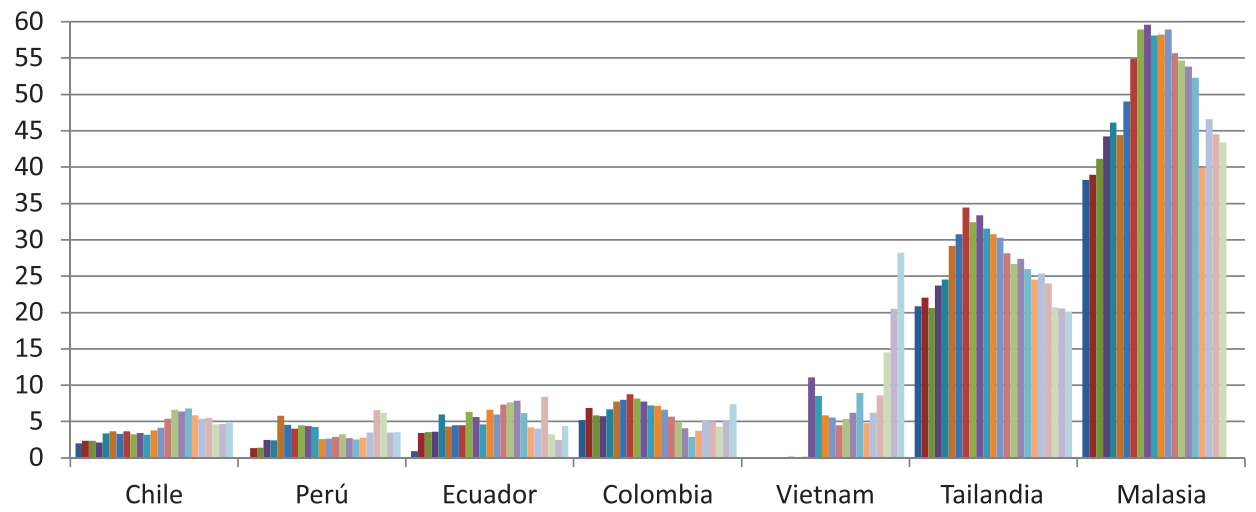

Figura 14. Participación porcentaje exportación de alta tecnología versus exportación industrial (1991-2013).

Fuente: World Development Report 2015 (Banco Mundial, 2016).

En la Figura 14 se observa que dentro de la producción manufacturera, las naciones de Asia del Sudeste realizan una fuerte incursión en la producción y exportación de equipos de alta tecnología, especialmente artículos electrónicos y de comunicaciones (Abdullah, 2010). Logran posicionarse en renglones tecnológicamente exigentes, porque los Estados han desarrollado visiones estratégicas para superar taras que los limitaban a la producción de materias primas y actividades de baja tecnología e ingreso, a través de planes quinquenales y programas a largo plazo para cualificar su gente, invertir en infraestructura y tecnología, para ofrecer estímulos adecuados a las firmas internacionales que se interesan en desarrollar negocios conjuntos. Estas incursiones no son carentes de riesgo, debido a que compiten en mercados exigentes que obligan a una constante innovación e inversiones, pero son las que han producido un gran cambio en los flujos globales de comercio y tecnología. En la gráfica anterior se observa cómo la participación en el total industrial ha decaído en los últimos diez años en Tailandia y Malasia, mientras que en Viet Nam aún está en franco crecimiento. Experiencias de Japón, Taiwán, Singapur, China y Corea (Palma, 2009) les han demostrado que tanto el Estado como las empresas locales deben continuar invirtiendo, desarrollando nuevas tecnologías, capacidades humanas y empresariales para permanecer competitivos en los sectores líderes. Las experiencias positivas muestran un número cada vez más amplio de nuevas transnacionales y marcas de esos países en el mundo, junto con las japonesas, estadounidenses y europeas. 


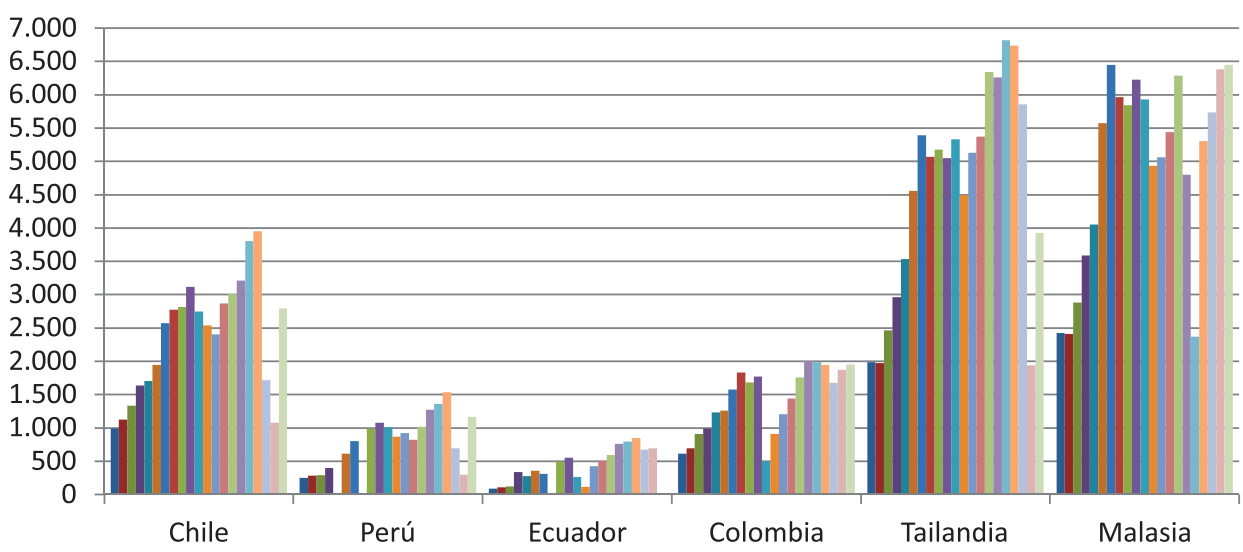

Figura 15. Número de patentes registradas por residentes y número de residentes 1991-2011.

Fuente: World Development Report 2015 (Banco Mundial, 2016).

La innovación tecnológica tiene que soportarse en nuevos procesos y productos (Kim, 2001), razón por la cual un buen indicador del tipo de inversión que se hace en un país es el número de patentes registradas. A pesar de que la distancia con países como Corea, Japón o China es muy amplia, se observa en la Figura 15 una positiva tendencia en los registros de Tailandia y Malasia, países que invierten cada vez más en centros de desarrollo tecnológico y actividades conjuntas con subsidiarias de firmas transnacionales. El liderazgo en Malasia ha sido aportado por el Estado en planes quinquenales y prospectivos a través del fomento del desarrollo tecnológico en las industrias electrónicas, automotriz, petroquímica y de multimedia (Abdullah, 2010), como única forma de penetrar en sectores de mayor valor agregado y demanda mundial. En el Pacífico suramericano solo Chile presenta una moderadamente favorable dinámica de este indicador, evidenciando que el modelo exportador centrado en commodities es poco dinámico tecnológicamente, porque es simple y escasamente se enlaza con otras industrias locales. Y los mejores avances en innovación de Chile se encuentran en su sector agroindustrial, no en el manufacturero. 


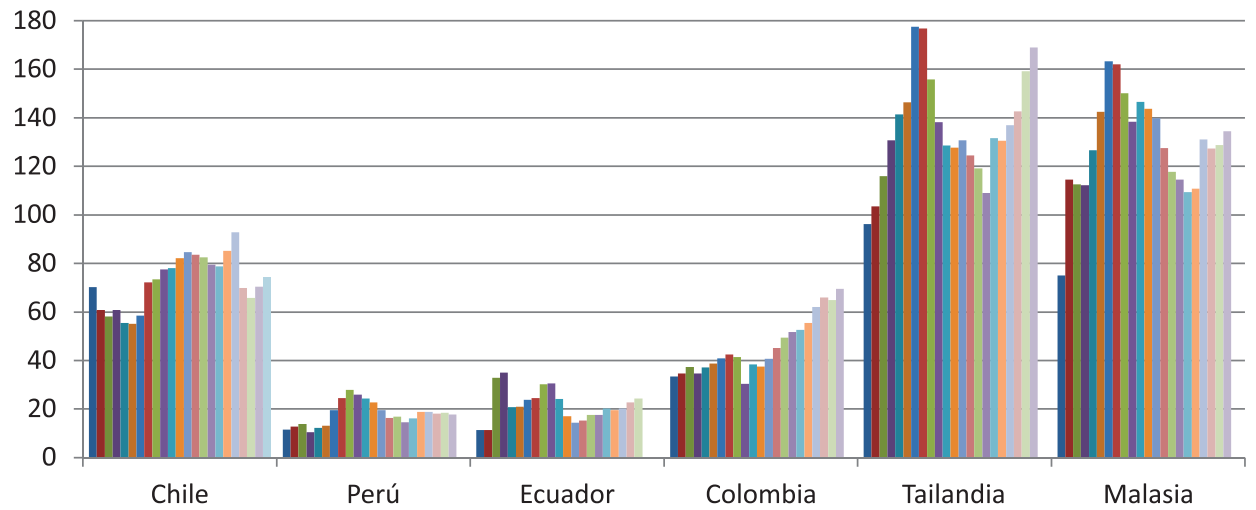

Figura 16. Crédito doméstico del sector bancario 1991-2013 (porcentaje PIB).

Fuente: World Development Report 2015 (Banco Mundial, 2016).

¿Cómo se financian las crecientes actividades productivas y tecnológicas? Se puede considerar que el crédito es eficiente cuando tiene la capacidad de irrigar tanto las viejas como las nuevas iniciativas económicas de un país. El crédito bancario en los países asiáticos surge de un equivalente volumen de ahorro interno que es canalizado por el Estado y la banca a las actividades productivas. En la Figura 16 se aprecia la amplia cobertura que logra la financiación bancaria en Tailandia y Malasia, que ocupa un poco más del valor de un año del PIB en financiación. También se aprecia cómo sufrió con la crisis de 1997, que ha sido superada en períodos posteriores. En los cuatro países suramericanos se registran bajas coberturas, especialmente en Perú y Ecuador, lo que indica que la penetración del crédito es modesta en la economía, es decir, que gran parte de los agentes empresariales del campo y la ciudad no tienen acceso al crédito o lo usan poco, bien sea por un escaso ahorro nacional, por baja reinversión de los grandes inversionistas, por los altos costos financieros o por deficiencias institucionales que terminan limitando la capacidad expansiva de la economía. El uso racional del crédito ayuda a la generación de un círculo virtuoso industrial y exportador que está cambiando rápidamente la situación de las naciones asiáticas.

DOMINANCIA DEL "CONSENSO DE WASHINGTON" EN EL PACÍFICO SURAMERICANO VERSUS PRAGMATISMO DESARROLLISTA ASIÁTICO

Los países asiáticos y latinoamericanos practicaron, especialmente después de la Segunda Guerra Mundial, claras políticas de industrialización 
aplicando la estrategia de "sustitución de importaciones", con gran apoyo de las Naciones Unidas a través de la Comisión Económica para América Latina (Cepal) con sede en Santiago de Chile, y de la Comisión Económica y Social para Asia y el Pacífico (Cespap) con sede en Bangkok (Tailandia). Una vez conseguidos importantes logros con el desarrollo de nuevas industrias locales, así como con inversiones conjuntas con empresas transnacionales, hacia la década del 80 se experimentaron las limitaciones propias del bajo ingreso de los mercados locales (Abdullah, 2010; Kuei-Lin \& HsuehLiang, 2003). Este compartido cuello de botella coincidió en América Latina con la grave crisis de la deuda externa en los 80 (Ocampo, Stallings, Bustillo, Velloso \& Frenkel, 2014), un ambiente traumático que no propició el surgimiento de iniciativas creativas para transformar el modelo productivo de manera que las importantes industrias creadas recuperaran sus equilibrios con otras estrategias de desarrollo, que superaran el enfoque de sustitución de importaciones y favorecieran la producción industrial exportable.

Los niveles de industrialización logrados por diferentes países de América Latina no fueron mínimos: de acuerdo con Astori (1980, p. 1389) la participación de la producción industrial en el producto interno bruto o "grado de industrialización" llegó a ser en 1973 del 32,3\% para Argentina, 26,2 \% para Brasil, 30,2 \% para Chile, 23,9\% para México, 18,8 \% para Colombia, $18 \%$ para Perú o $24 \%$ para Uruguay. Estos valores muestran que el esfuerzo industrializador y las políticas industriales y de protección comercial funcionaron hasta los años 70 , acercando la estructura productiva a niveles intermedios en comparación con países europeos, y superando en esos años a muchas naciones en proceso de desarrollo del Este y Sur del Asia (Fukasaku, 2004), países que apenas iniciaban el "take-off" o proceso de rápido crecimiento económico. Estos sí fundamentaron su despegue con gran aporte de capital, mercados y tecnologías extranjeras, y fuerte presencia exportadora.

La confusión y la frustración en los países de Latinoamérica en los 80 fueron aprovechadas por las instituciones financieras lideradas por Estados Unidos (Fondo Monetario Internacional, Banco Mundial) para presionar a las élites de la subregión a acogerse a un paquete de fuertes reformas políticas que terminó denominándose el "Consenso de Washington" (CW), políticas que privilegiaron el saneamiento de las endeudadas finanzas estatales de los países de la región, para pagar la deuda externa con la banca internacional. Parte clave de la estrategia consistió en exigir la reducción del papel del Estado a su más mínima expresión, a través de una política de choque que incluyó disminución rápida del 
personal en la administración institucional y en empresas estatales, eliminación de subsidios al consumo social y a las tasas de interés para actividades productivas, además de un fuerte programa de privatización de las empresas estatales, con cuyos dineros se cancelaron las deudas estatales. Un elemento clave para considerar es que estas empresas constituían en prácticamente todos los países en desarrollo hacia los años 80 su principal base tecnológica, el lugar donde se transformaban parte de sus materias primas y se producían bienes de mayor sofisticación, donde se formaban sus técnicos y gerentes. Y los ministerios y agencias estatales tenían no pocas funciones de desarrollo productivo, extensión tecnológica, crédito a campesinos e industriales, y cualificación de personal ${ }^{10}$.

Por su parte, en el Asia, las fuertes políticas proteccionistas y el amplio papel inversionista del Estado continuó creando infraestructura física y empresarial a través de masivos estímulos para vincularse a mercados de exportación global. Expresado en términos del recientemente fallecido arquitecto del desarrollo de Singapur, Goh Keng Swee (citado por Chen, 2016, p. 19): [the laissez-faire policies of the colonial era] had led Singapore to a dead end, with little economic growth, massive unemployment, wretched housing, and inadequate education [...] thus [we] had to try a more activist and interventionist approach". For example, the Economic Development Board, set up in 1961, geared Singapore's industrial strategies, labor policy, and education system towards meeting Singapore's economic goals by way of tax incentives, investment in strategic industries, and global network building. In its heyday, there were more than 600 state-owned enterprises and government-linked companies, many of which were run on commercial principles and were profitable and internationally competitive from the outset.

La mayoría de naciones asiáticas del Este y Sureste, siguiendo la ruta de desarrollo industrial-exportador japonés del "ganso líder" (Palma, 2009) consiguieron superar etapas primarias del desarrollo industrial y lograron consolidar una senda de transformación de sus economías y sociedades en dirección a la participación amplia en los mercados internacionales a través de un mayor desarrollo industrial y tecnológico,

\footnotetext{
${ }^{10}$ En Colombia, el ICA (Instituto Colombiano Agropecuario) desarrollaba nuevas variedades de semillas de alimentos; el IDEMA (Instituto de Mercadeo Agropecuario) compraba y regulaba las cosechas de cereales; el IFI (Instituto de Fomento Industrial) cofinanciaba inversiones industriales, parte de ellas con empresas transnacionales; los bancos estatales y privados ofrecian créditos con bajas tasas de interés a cultivadores, industriales y comerciantes, entre otras instituciones claves. La mayoría de ellas fueron reducidas a un mínimo a través de la privatización (con cambio de énfasis funcional) a partir del paquete de reformas recomendado por el Consenso de Washington desde fines de los 80.
} 
con creación de empleo calificado y manejada liberalización económica, en la medida que fortalecían sus capacidades productivas e institucionales, dando mayor participación al capital privado y más amplias libertades a sus ciudadanos. En dichos países del Asia, las empresas estatales no fueron privatizadas de facto (tipo Consenso de Washington), sino reestructuradas y potenciadas para lograr estadios superiores de tecnología y acceso a mercados internacionales, con programas progresivos de privatización y el mantenimiento de la regulación, estímulos impositivos, especialmente en sectores considerados como estratégicos, incluyendo la inversión directa estatal. Las experiencias fueron diferentes en los distintos países del Asia, pero, en general, las empresas estatales gradualmente se desarrollaron dando origen a modernos consorcios estatales y privados (como en Taiwán, Malasia o China), a fuertes conglomerados privados (como los "chaebol" coreanos) o realizando alianzas con grandes transnacionales (como en Malasia, Tailandia o China).

Las industrias desarrolladas en el Asia se volvieron activas exportadoras globales de tecnología y presentan una dimensión clara: impulsadas primero por Japón (Palma, 2009), y luego por Corea, Taiwán y China, el comercio intraindustrial entre los países asiáticos crece continuamente, mientras la regulación estatal continúa propiciando la creación de centros tecnológicos públicos y privados, de marcas locales, el registro de nuevas patentes, en pocas palabras, "endogeneizan" la tecnología y avanzan en la creación científica mientras se internacionalizan. Y fruto de ello, los países líderes del Asia incursionan crecientemente en el mercado internacional con marcas propias como Hyundai, Kia o Samsung de Corea, Huawei, Alibaba o Byd de China, Foxconn Technology, Taiwan Mobile o Nvidia de Taiwan, Petronas y Proton de Malasia, entre muchas otras. Las privatizaciones en el Asia se realizaron gradualmente, sin sacrificar las bases productivas creadas a través de la estrategia de sustitución de importaciones, sin distinguir si los Estados eran capitalistas o comunistas, es decir, más generadas por el pragmatismo que por la ideología.

En el Asia del Este y Sudeste no se presentó ninguna "crisis de deuda" en los $80 \mathrm{y}$, por tanto, no tuvieron en esos años mayor cabida las recomendaciones del Consenso de Washington al tiempo con Latinoamérica, pero con la crisis financiera de 1997-1998 se reveló que la apertura de la cuenta de capital en los países emergentes del Asia - una de las recomendaciones centrales del $\mathrm{CW}$ - había sido llevada hasta niveles no manejables para dichos países. Incluso influyentes economistas, como Jagdish Bhagwati, muy cercanos a otras políticas del CW 
como la liberalización del comercio y la apertura a la inversión extranjera, criticaron con dureza la veloz apertura de las cuentas de capital:

Starting in Thailand in the summer of 1997, the Asian financial crisis swept through Indonesia, Malaysia, and South Korea, turning the region's economic miracle into a debacle....The crisis, precipitated by panic-fueled outflows of capital, was a product of hasty and imprudent financial liberalization, almost always under foreign pressure, allowing free international flows of short-term capital without adequate attention to the potentially potent downside of such globalization. There has been no shortage of excuses and strained explanations scapegoating the victims, suggesting they committed hara-kiri instead of being slaughtered. It is hard not to conclude that the motivation underlying these specious explanations is a desire to continue to maintain ideological positions in favor of a policy of free capital flows or to escape responsibility for playing a central role in pushing for what one might aptly call gung-ho international financial capitalism. (Bhagwati, 2004, pp.199-200; citado en Kanbur, 2008, p. 10)

Con la adopción de las políticas del Consenso de Washington desde fines de los años 80, los Estados nacionales en Latinoamérica dejaron de impulsar una política industrial ligada a la internacionalización a través de sus empresas industriales (Cepal, 2005). Las empresas privatizadas (compradas por nacionales o transnacionales) pasaron a concentrarse en aprovechar los mercados locales y poco creció la inserción en cadenas globales de valor ${ }^{11}$. La crisis del modelo de industrialización por sustitución de importaciones en los 80 en Latinoamérica significó un retroceso en el campo industrial y nunca pudo internacionalizarse significativamente. Países grandes de la región, como México, se convirtieron ya en los años 90 en plataforma industrial exportadora a los Estados Unidos a través de grandes transnacionales, pero con escaso know-how y valor agregado locales (García, 2009, varias págs.), quedando muy frágiles ante posibles cambios en las políticas comerciales de su vecino del norte. Brasil continuó siendo gran exportador industrial al Mercosur, pero su dinámica mundial cambió en los años 90 el énfasis hacia la exportación de materias primas con menor valor agregado: soya, mineral de hierro o carne vacuna (Salama, 2012). Los países del actual Grupo Alianza Pacífica (AP) de Suramérica - buenos aplicadores de las recomendaciones del CW - como se ha visto, explican actualmente entre el 70 y $90 \%$ de sus

\footnotetext{
${ }^{11}$ Con excepción hecha de México, que se volcó casi exclusivamente al mercado de los Estados Unidos desde 1994 con su ingreso al Tratado de Libre Comercio de Norte América.
} 
exportaciones con materias primas de bajo valor agregado local, mientras que cuentan con poca exportación de bienes manufacturados. Incluso Colombia, la economía más diversificada entre los cuatro, ha decrecido rápidamente en su componente exportador manufacturero, a la par con el ascenso de la exportación petrolera (Figura 11) y el abandono de políticas industriales ligadas a la internacionalización.

\section{Los "consensos" de Beijing y de Washington}

El término "consenso" tiene una clara implicación de "acuerdo general entre partes". Los dos tipos de "consensos" aquí analizados, el de Washington (CW) y el de Beijing (CB), en realidad están lejos de ser lo que la palabra quiere significar. El de Washington, porque no se consensuó, ni con las élites latinoamericanas, ni con representantes de sus sociedades, pues se impuso como condicionamiento para aprobar los préstamos del FMI desde la crisis de deuda de los 80 . Y el de Beijing, porque las autoridades chinas no tienen oficialmente ningún "consenso", ni expresan querer recomendar, o condicionar, algún tipo de modelo en su inversión o financiación a otros países, ni tampoco que deseen contraponer el $\mathrm{CB}$ al CW. El término fue creado por el periodista y académico Joshua Ramo, quien trabajó en el Reino Unido en tiempos del Gobierno de Tony Blair, y se refiere a una especie de modelo o ruta de desarrollo que China habría seguido, y eventualmente, otros países en desarrollo querrían adoptar:

To the degree China's development is changing China it is important; but what is far more important is that China's new ideas are having a gigantic effect outside of China. China is marking a path for other nations around the world who are trying to figure out not simply how to develop their countries, but also how to fit into the international order in a way that allows them to be truly independent, to protect their way of life and political choices in a world with a single massively powerful centre of gravity. I call this new physics of power and development the Beijing Consensus. It replaces the widely-discredited Washington Consensus, an economic theory made famous in the 1990s for its prescriptive, Washington-knows-best approach to telling other nations how to run themselves. (Ramo, 2004, p. 3)

Las principales características expuestas por Ramo sobre el CB podrían resumirse en tres principios (citado por Li, Brødsgaard \& Jacobsen, 2009, p. 299):

1. Desarrollo nacional a través de la experimentación política (prueba y error a nivel local) y de la innovación.

2. Desarrollo sostenible en el tiempo, fundamentado en la equidad social, $\mathrm{y}$ 
3. No interferencia en la libre determinación de las naciones por terceros poderes.

Sin embargo, dada la tradicional influencia política de Estados Unidos en las naciones latinoamericanas, estas siguieron las prescripciones del $\mathrm{CW}$, las cuales van en contravía de los tres principios practicados por China y esbozados por Ramo: el CW prescribió "recetas genéricas" ("One size fits all"), llamadas "programas de ajuste", para superar la crisis de la deuda externa, considerando muy poco las distintas alternativas que podrían haber implementado naciones tan diferentes, como por ejemplo Ecuador y Brasil. Dichas medidas de choque uniformes afectaron los tejidos sociales de los países, disminuyendo la relativa equidad social lograda con la industrialización, especialmente por el desempleo causado por la reducción de las nóminas estatales, la eliminación de subsidios a la gasolina o a las tasas de interés para la producción, y en general los recortes a los presupuestos sociales de los gobiernos, y generando crisis sociales y económicas que derivaron en la que se conoce como "la década perdida de Latinoamérica". Este tipo de condicionamientos forzosos violaron la autonomía de los Estados del área, imponiéndoles políticas que implicaron grandes sacrificios.

El mismo FMI, actualmente bajo la dirección de la francesa Christine
Lagarde, reconoce autocríticamente algunos de los errores cometidos por esa institución en el pasado reciente. En artículo publicado en la revista del FMI Finance and Development (Ostry, Loungani \& Furceri, 2016) se acepta que:

There are aspects of the neoliberal agenda that have not delivered as expected. Our assessment of the agenda is confined to the effects of two policies: removing restrictions on the movement of capital across a country's borders (so-called capital account liberalization); and fiscal consolidation. An assessment of policies to reduce fiscal deficit and debt levels (rather than the broad neoliberal agenda) reaches three disquieting conclusions:

1) The benefits in terms of increased growth seem fairly difficult to establish when looking at a broad group of countries. 2) The costs in terms of increased inequality are prominent. 3 ) Increased inequality in turn hurts the level and sustainability of growth. Even if growth is the sole or main purpose of the neoliberal agenda, advocates of that agenda still need to pay attention to the distributional effects $[\ldots]$

Economic theory leaves no doubt about the potential advantages" of capital account liberalization, which is also sometimes called financial openness $[\ldots]$ financial openness has distributional effects, appreciably raising inequality. Moreover, the effects of openness on inequality are 
much higher when a crash ensues. The mounting evidence on the high cost-to-benefit ratio of capital account openness, particularly with respect to short term flows, led the IMF's former First Deputy Managing Director, Stanley Fischer, now the vice chair of the U.S. Federal Reserve Board, to exclaim recently: "What useful purpose is served by short-term international capital flows?" Among policymakers today, there is increased acceptance of controls to limit short-term debt flows that are viewed as likely to lead to - or compound - a financial crisis [...] J. Stiglitz noted that in the early years of its move to neoliberalism, Chile imposed "controls on the inflows of capital, so they wouldn't be inundated", as, for example, the first Asian-crisis country, Thailand, was a decade and a half later. (Ostry, Loungani \& Furceri, 2016, p. 39-41)

Uno de los sacrificios estratégicamente más importantes realizados por los países de Latinoamérica se derivó de la aceptación del CW, que marcó una gran divergencia con la ruta seguida por los países del Sur y Este Asiático: los primeros sacrificaron su liderazgo industrial, mientras los segundos lo convirtieron en un eje central de su desarrollo. Por ello, las exportaciones de los cuatro países del Pacífico suramericano analizadas en este estudio se concentran hoy en materias primas, y no en bienes industriales. Por el contrario, los asiáticos que también ayer vendían materias primas, las compran hoy, las procesan y las reexportan como productos con mayor valor agregado y tecnología a todo el mundo, incluida Latinoamérica.

En la contraposición académica de los dos "modelos", diversos autores consideran que más que un $\mathrm{CB}$, existiría un "modelo chino o asiático" de desarrollo (Li et al., 2009; Chen, 2016; Palma, 2009), por el cual se practicarían ciertos principios contemplados en el $\mathrm{CW}$-como la liberalización comercial, las tasas de cambio competitivas y aún las privatizaciones-, pero siempre, y de manera muy importante, aplicándolas gradualmente en el espacio y el tiempo, según las condiciones propias de cada país. Esta gradualidad y respeto por las condiciones de cada país, sumados a la clara y poderosa utilización de las palancas del Estado para dinamizar e internacionalizar sus economías y sociedades, parecen ser la clave del éxito de los desarrollos logrados por diferentes naciones del Asia durante las últimas décadas.

Las diez recomendaciones en que se basó el CW parecen poder ser saludablemente aplicables a las naciones que han implementado exitosamente - con gradualidad, identidad nacional y sapiencia-, políticas de desarrollo que se apoyan en políticas industriales más internacionalización que, junto a alianzas globales para obtener tecnología, han capacitado masivamente a su población y mantenido adecuados 
márgenes de solvencia moral y calidad de vida. Es decir, son "medidas de ajuste" para naciones maduras. El haber logrado la aplicación de dichas formulaciones a países en etapas primarias o medias de desarrollo, sin duda produjeron los retrocesos experimentados en Latinoamérica y naciones del África (Palma, 2009). En este sentido, el CW no respetó lo que el "modelo asiático/chino" ha practicado. Sin embargo, teniendo en cuenta que los países avanzan, mantienen una dinámica transformadora y se liberalizan cuando alcanzan estándares competitivos, adoptando nuevas políticas, el profesor Chen de la Universidad Nacional de Singapur analiza cómo China hace esfuerzos por internacionalizar su moneda (el renminbi -RMB-), para lo cual está realizando profundas reformas en sus políticas financieras:

In the context of the Scheme (of Rmb internationalization), the merits of China's various reform approaches are rather in line with the values of neoliberal economics underlying the Washington Consensus, as evidenced by the reform measures China is currently pushing in order to internationalize Rmb [...] Given the neoliberal nature of the Scheme and various other measures relating to the implementation of the Scheme, it is fair to conclude that Beijing in fact follows the policy prescriptions under the Washington Consensus for creating a potential game changer for the global financial world. (Chen, 2016, p. 27)
El pragmatismo del "modelo Chino" no le impediría adoptar las políticas que considere convenientes para continuar desarrollando su economía y sociedad - incluidas las del $\mathrm{CW}$-, porque el país ha alcanzado un grado elevado de acumulación de reservas internacionales y presencia en los negocios del planeta, que le está exigiendo propulsar su moneda al nivel de otras como el USD, el euro, el yen y la libra esterlina, que se usan como monedas de cambio y de reserva en las transacciones globales. La economía china estaría ganando madurez para adoptar políticas que no aceptó en el pasado, porque considera que en el presente pueden ser ventajosas para sus intereses nacionales. Y también en el comercio internacional, China y demás países asiáticos compiten con las reglas de la liberalización comercial, así en sus políticas internas seleccionen cuáles de ellas adoptan y en qué momentos: no aceptaron las medidas tipo "one size fits all" del $\mathrm{CW}$ para Latinoamérica.

\section{CONCLUSIONES}

Las cuatro naciones del Pacífico suramericano analizadas aquí han definido su inserción al comercio global en el siglo XXI como productores y exportadores de materias primas. Los buenos precios internacionales que tuvieron durante diez años les permitieron mejorar sus ingresos, su infraestructura económica y social, 
reducir sus niveles de pobreza y avanzar en términos de educación y salud. Sin embargo, a la par con la explotación de materias primas se sacrificó el desarrollo industrial estimulado desde mediados del siglo $\mathrm{XX}$, perdiendo empleos calificados y la inserción en cadenas internacionales con mayor valor agregado. Y con la reciente terminación del ciclo favorable de precios de las materias primas, se enfrentan en la actualidad a una significativa reducción de sus ingresos y, por tanto, a una redefinición de sus modelos económicos y de inserción en la economía mundial. Chile presenta, incluso desde inicios del siglo XX, mejores condiciones de organización social, menores índices de corrupción y más inserción internacional que sus vecinos del norte del Pacífico suramericano, lo que le ofrece horizontes más amplios para diversificar su economía, a través de la agricultura y agroindustria. En Colombia, a pesar de la enorme devaluación de su moneda desde 2014, ni la producción industrial ni las exportaciones manufactureras responden, situación que ha ocasionado una disminución de su ritmo de crecimiento y que no haya mayores luces acerca del tipo de desarrollo futuro.
Por su parte, las naciones de Asia del Este y Sureste no sacrificaron sus desarrollos industriales con la crisis financiera hacia 1997, sino que potenciaron y profundizaron los procesos de internacionalización productiva, tecnológica y comercial. Las grandes transnacionales industriales no van hoy a producir a Suramérica, sino al Asia, y especialmente a China. Las comprometidas y pragmáticas políticas de desarrollo local aplicadas con fuerte vinculación con los mercados internacionales_-, sugieren que un modelo de desarrollo asiático/chino ha ofrecido condiciones más realistas, más confiadas en las capacidades de sus poblaciones, para que países anteriormente pobres, consigan desarrollos que les otorgan capacidades propias para insertarse productiva $\mathrm{y}$ ventajosamente en la rápida globalización de hoy. De esta manera, la actual vinculación comercial y tecnológica de los países del Pacífico suramericano con China y otras naciones del Asia, asume rasgos semejantes a los de una relación sur-norte, típica del antiguo orden internacional. 


\section{REFERENCIAS}

Abdullah, M. (2010). Malaysian Industrial Development. Kuala Lumpur. MIDA.

Astori, D. (1980). Algunas características de la industrialización en América Latina. Revista Comercio Exterior, 30(12), 1386-1400.

Banco de la República de Colombia. (2016). Cuentas de la balanza de pagos. Recuperado de www.banrep.gov.co

Banco Mundial. (2016). World Development Report 2015. World Development Indicators. Retrieved from http://www.worldbank.org/en/publication/ wdr2015

Birle, P. (Ed.). (2013) Chile a 40 años del golpe de Estado. Repercusiones y memorias. Berlín: Ibero-Amerikanisches Institut.

Chen, W. (2016). Size Matters? Renminbi Internationalization and the Beijing Consensus. Working Paper 2016/002 - NUS Centre for Asian Legal Studies. Singapur: National University of Singapur.

Chuhue, R., Na, L. J. \& Coello, A. (Ed.). (2012). La inmigración china al Perú. Arqueología, historia y sociedad. Lima: Editorial Universitaria, Universidad Ricardo Palma e Instituto Confucio.

Comisión Económica para América Latina -Cepal-. (2005) Más allá del Consenso de Washington: una agenda de desarrollo para América Latina. México: Cepal.

Comisión Económica para América Latina -Cepal-. (2016) La inversión extranjera directa en América Latina y el Caribe. Santiago de Chile: Cepal.

Corporación Nacional del Cobre de Chile Codelco S.A. (2003-2015). Informes anuales de estados financieros consolidados, años 2003 a 2015. Chile: Codelco.

Empresa Colombiana de Petróleos -Ecopetrol-. (2016) Estados financieros 2015. Recuperado de http://www.ecopetrol.com.co/documentos/inversionistas/ PG-consolidado-2015.pdf 
Apuntes CENES Volumen 37, Número 65

enero - junio 2018. Págs. 77-116

Fukasaku, K. (2004). Overview: Miracle, Crisis and Beyond. OECD Development Centre, Paris. Retrieved from https://www.oecd.org/pcd/31970815. pdf

García, H. (2009). La situación de la industria automotriz en México. México:Colegio de la Frontera (COLEF).

Hausmann, R., Wang, J. \& Rodrik, D. (2005). What you export matters. Working Paper 11905. Cambridge, MA: National Bureau of Economic Research.

Ostry, J., Loungani, P. \& Furceri, D. (2016, June). Neoliberalism: Oversold? Magazine Finance and Development, IMF.

Kanbur, R. (2008). The Co-Evolution of the Washington Consensus and the Economic Development Discourse. Retrieved from www.people.cornell.edu/ pages/sk145

Kim, L. (2001) La dinámica del aprendizaje tecnológico en la innovación. Recuperado de http://www.oei.es/salactsi/limsu.pdf

Kuei-Lin, C. \& Hsueh-Liang, W. (2003) Policy Design and Implementation of Taiwan's Privatization. Retrieved from https://www.oecd.org/daf/ca/corporategovernanceofstate-ownedenterprises/2482165.pdf

Lavaux, S. \& Ochoa, P. (2010). Estado del arte. El conflicto en Perú. Bogotá: Facultades de Ciencia Política y de Relaciones Internacionales, Centro de Estudios Políticos e Internacionales -CEPI-, Universidad del Rosario.

Li, X., Brødsgaard, K. E. \& Jacobsen, M. (2009). Redefining Beijing Consensus: Ten Economic Principles. Denmark: Asia Research Centre, Copenhagen Business School.

Mahtaney, P. (2007). India, China and Globalization - The Emerging Superpowers and the Future of Economic Development. Palgrave: Macmillan Eds.

Ocampo, J. A., Stallings, B., Bustillo, I., Velloso, H. \& Frenkel, R. (2014). La crisis latinoamericana de la deuda desde la perspectiva histórica. Santiago de Chile: Cepal. 
Palma, J. G. (2009). Flying Geese and Waddling Ducks: The Different Capabilities of East Asia and Latin America to "Demand-Adapt" and "Supply-Upgrade" their Export Productive Capacity. In M. Cimoli, G. Dosi \& J. Stiglitz (eds.), The Political Economy of Capabilities Accumulation: the Past and Future of Policies for Industrial Development. Oxford: Oxford University Press, 2009.

Ramo, J. C. (2004). The Beijing Consensus. London, UK: The Foreign Policy Centre.

Salama, P. (2012). China-Brasil: industrialización y "desindustrialización temprana”. Revista Cuadernos de Economía, 31(56).

Tan, C. I. (2012). Managing a Plural Society: Issues and Challenges of Multiculturalism in Malaysia. In The Asian Conference on Cultural Studies, Official Conference Proceedings 2012.

Torres, J. (2016, marzo). El reto de las exportaciones de China para los países en desarrollo. Revista Análise Económica, 34(65), 345-377.

Ulloa, C. (2006). 25 años de inestabilidad política en el Ecuador. Revista Brújula, 6(9), 37-53.

Walter, R. (2006). Geschichte der Weltwirtschaft. Eine Einführung. Köln, Deutschland: Böhlau Verlag. 